\title{
The Triple Point of Oxygen In Sealed Transportable Cells
}

\section{George T. Furukawa}

National Bureau of Standards Gaithersburg, MD 20899

\begin{abstract}
The triple points of oxygen samples sealed in miniature pressure cells were investigated by means of adiabatic calorimetry. The triple point of a 99.999 percent pure commercial oxygen sample was found to be $0.94_{0} \mathrm{mK}$ higher than that of an "ultra-pure" sample prepared by thermal decomposition of potassium permanganate $\left(\mathrm{KMnO}_{4}\right)$. The higher value is attributed principally to argon impurity in the commercial oxygen. The results of eight sets of observations using six thermometers, calibrated on the International Practical Temperature Scale of 1968 as maintained at the National Bureau of Standards, and two sealed cells of the ultra-pure oxygen show a range of $0.17_{8} \mathrm{mK}$. The capsuletype platinum resistance thermometers that have been used are shown to have
\end{abstract}

\begin{abstract}
outstanding stability and the multiple calibrations made on them at the National Bureau of Standards extending over six years are shown to be consistent to within $0.15 \mathrm{mK}$ at $54.361 \mathrm{~K}$. The results of measurements on an internationally circulated sealed cell of commercial oxygen show its temperature to be 0.58 , $\mathrm{mK}$ higher than those of the ultra-pure oxygen.
\end{abstract}

Key words: adiabatic calorimeter; International Practical Temperature Scale of 1968; melting point; miniature oxygen cell; oxygen preparation; oxygen triple point; platinum resistance thermometer; temperature fixed point; triple point.

Accepted: March 19, 1986

\section{Introduction}

The triple point of oxygen $(54.361 \mathrm{~K})$ is one of the defining fixed points of the International Practical Temperature Scale of 1968 (IPTS-68) [1]'. In a report on the international comparison of triple point temperatures of pure gases sealed in miniature pressure cells [2], the results on oxygen showed a range of values of about $2 \mathrm{mK}$ while the results on argon, neon, and hydrogen showed a range of about 0.4 to $0.5 \mathrm{mK}$. With oxygen, the lower temperatures that were realized were consid-

About the Author: George T. Furukawa is with the Temperature and Pressure Division in the NBS Center for Basic Standards.

${ }^{1}$ Figures in brackets indicate literature references. ered to be representative of purer samples and the higher temperatures to be due to the presence of argon which raises the apparent triple point $[3,4]$. The amount of argon that was known to be present in some of the oxygen samples could not completely account for the higher values. This paper describes, as part of the continuing research at the National Bureau of Standards (NBS) on the reproducibility of the triple points of pure substance sealed in cells, the measurements of the triple points of three oxygen samples. One of the measurements was on the oxygen cell (designated IMGC- $8 \mathrm{O}_{2}$ ) that was used in the international comparison of fixed points; it was prepared at the Instituto di Metrologia "G. Colonnetti" (IMGC, Italy) using commercially available high-purity oxygen 


\section{Journal of Research of the National Bureau of Standards}

[5]. One of the other two samples was also from a commercial source. The third sample was prepared by thermal decomposition of potassium perman. ganate $\left(\mathrm{KMnO}_{4}\right)$ under meticulous conditions to yield a sample of ultra-high purity. Measurements were obtained on two cells of this prepared oxygen. The measurements on each of the samples show reproducibility of about \pm 0.02 to $\pm 0.03 \mathrm{mK}$, but the range of the triple points of the three samples is about $1 \mathrm{mK}$.

As an integral part of the investigation, the results of the measurements using six capsule-type standard platinum resistance thermometers were compared to determine the stability of these thermometers and the consistency of their calibrations at NBS. (Henceforth, for convenience, the capsuletype platinum resistance thermometers that meet the specifications of the IPTS-68 [1] will be referred to by the abbreviation SPRT's.) As shown previously in the work on the triple point of argon [6], the present measurements will also show that these six SPRT's have outstanding stability and that the NBS calibrations on them over a number of years are highly reproducible.

\section{Method and Experimental Procedure 2.1 Method}

The technique for determining the triple points of pure gases sealed in miniature pressure cells involves the measurement of equilibrium temperatures at various known ratios of liquid-to-solid phases of the sample under adiabatic conditions. (Under the conditions of the experiment, the vapor volume is larger than 10 times the sum of the volumes of the two condensed phases. Hence, the change in the vapor volume over the range of various fractions melted was considered negligible and the amount of impurities in the vapor to be constant.) Similar techniques have been used for many years in the calorimetric determination of chemical purity and the triple-point (or the melting point) of a variety of substances [7].

For an "ideal" system (where Raoult's law is valid and the impurities remain segregated in liquid solution), the equilibrium at temperature $T$ between a liquid mixture and a pure solid of the major component can be represented by

$$
\ln \frac{\lambda_{l}^{0}(T)}{\lambda_{l}(T)}=\frac{\Delta H}{R}\left(\frac{1}{T}-\frac{1}{T_{0}}\right)
$$

where $\lambda_{1}^{0}(T)$ is the absolute activity of the pure liquid at temperature $T$ and similarly $\lambda_{1}(T)$ is the abso- lute activity of the same substance in the particular liquid mixture [8]. $T_{0}$ is the melting (or freezing) point of the pure solid, $R$ is the molar gas constant, and $\Delta H$ is, in order to simplify the equilibrium relation to (1), the average molar heat of fusion over the temperature interval $T$ to $T_{0}$ (see reference [9] for an extended relation). Since $\lambda_{1}^{0}(T) / \lambda_{1}(T)$ is greater than unity, $T$ is less than $T_{0}$. From the Gibbs-Duhem relation, for an ideal mixture

$$
\lambda_{1}=\left(1-x_{2}\right) \lambda_{1}^{0}
$$

where

$$
x_{2}=\mathrm{N}_{2} /\left(\mathrm{N}_{1}+\mathrm{N}_{2}\right)
$$

and $\mathrm{N}_{1}$ is the number of moles of the major component (oxygen) and $\mathrm{N}_{2}$ the number of moles of the minor component (impurities). By combining eqs (1) and (2), there is obtained

$$
-\ln \left(1-x_{2}\right)=\frac{\Delta H}{R T T_{0}}\left(T_{0}-T\right) .
$$

When $x_{2}$ is small (i.e., when the oxygen sample is highly pure), $-\ln \left(1-x_{2}\right)$ is approximately equal to $x_{2}$ and $T T_{0}$ and $T_{0}^{2}$ are nearly equal. Then eq (4) is approximately

$$
x_{2}=\frac{\Delta H}{R T_{0}^{2}}\left(T_{0}-T\right)
$$

For oxygen, $\Delta H=443.5 \mathrm{~J} \mathrm{~mol}^{-1}$ [10]; therefore, $\Delta H / R T_{0}^{2}$ evaluates to $0.01805 \mathrm{~K}^{-1}$ and eq (5) simplifies to

$$
x_{2}=0.01805\left(T_{0}-T\right) .
$$

Equation (6) indicates that in order for the temperature depression $\left(T_{0}-T\right)$ due to impurities to be less than $0.1 \mathrm{mK}, x_{2}$ must be less than $2 \times 10^{-6} \mathrm{~mol}$ fraction. (It is to be noted that compared to metals, the value of $\Delta H / R T_{0}^{2}$ for oxygen, as well as for most molecular substances, is relatively large. In the case of zinc, $\Delta H / R T_{0}{ }^{2}=0.0019 \mathrm{~K}^{-1}$, which indicates that the total impurity concentration must be one-tenth of that for oxygen or less than $0.2 \mathrm{ppm}$ in order for the temperature depression to be less than $0.1 \mathrm{mK}$.)

If the assumption that the impurities remain segregated in the liquid phase holds, then at equilibrium the impurity concentration in the liquid would vary inversely with the fraction $F$ of oxygen melted. Thus,

$$
x_{2}=x_{2}{ }^{*} / F,
$$




\section{Journal of Research of the National Bureau of Standards}

where $x_{2}{ }^{*}$ is the overall impurity concentration or the impurity concentration of the liquid when the oxygen is completely melted. When eqs (6) and (7) are combined, there is obtained

$$
x_{2}^{*} / F=0.01805\left(T_{0}-T\right)
$$

or

$$
\left(T_{0}-T\right)=55.40 x_{2}{ }^{*} / F \text {. }
$$

Equation (9) shows that the impurity concentration $x_{2}{ }^{*}$ can be obtained from the "slope" $\left(55.40 x_{2}{ }^{*}\right)$ of the linear relation of the observed equilibrium temperature $T$ versus $1 / F$. At $1 / F=0, T=T_{0}$, the triple point of pure oxygen. The temperature at $1 / F=1$ is that value when vanishingly small amount of solid oxygen is present in equilibrium. As mentioned earlier, the method [i.e., eq (9)] has been employed for many years in the determination of impurity concentration as part of the heat-capacity measurements because the fraction $F$ melted can be accurately determined and the difference in the equilibrium temperatures $\left(T_{0}-T\right)$ caused by the impurities can be amplified in accordance with the reciprocal of fraction melted [7]. The practice has been to observe a number of equilibrium temperatures at different fractions melted and obtain the "best values" of $x_{2}{ }^{*}$ and $T_{0}$.

In experimental situations, the results deviate more or less from the idealized equations given above due to many factors. First of all, in the case of oxygen, the commercially available high-purity material is obtained principally by separation from air and, hence, other components of air are expected to be present as impurities, e.g., nitrogen, argon, and other noble gases. Neon, krypton, and xenon have been reported to lower the freezing (liquidus) point of oxygen [3]. Both nitrogen and argon are known to form solid solutions with oxygen [11,12]. Most likely, in high-purity oxygen, the former three noble gases would also form solid solutions. Furthermore, oxygen and argon mixtures form a peritectic in the oxygen-rich region. The rather sparse experimental data suggest that the peritectic point composition is in the region of 80 to $85 \mathrm{~mol}$ percent oxygen [12,13]; the peritectic temperature is around $55.8 \mathrm{~K}$; and the "peritectic break" occurs at about $88 \mathrm{~mol}$ percent oxygen. In this oxygen-rich region of the system, the liquidus and solidus curves are very closely spaced. The samples for oxygen triple point measurements are expected to have small enough argon concentrations that they would behave as binary isomorphous systems [14] and that no peritectic reaction would be observed (i.e., there will be a "melting range"). The solid solution would be richer in argon than the liquid solution, making the equilibrium temperature $T$ greater than $T_{0}$, in contrast with the premise upon which eqs (1) to (9) were derived.

There are other considerations in the real experimental situations. Whenever the compositions of the liquid and solid phases are the same and remain the same, although the ratios of the amounts of the two phases are changed by melting, the equilibrium temperatures remain unchanged. This is the case with a 100-percent pure sample and with eutectic mixtures. The outstanding example of an eutectic is that of the tin-iron system with its eutectic composition at 0.001 mol-percent of $\mathrm{Fe}$ and the eutectic temperature only $8 \mathrm{mK}$ lower than the freezing point of pure tin [15]. Also, if the compositions of the liquid phase and of the solid phase in equilibrium remain unchanged, even though the ratios of the amounts of the two phases are changed, the equilibrium temperature will remain the same. The outstanding case of this is the ice bath, where there is an infinite amount of air present to maintain the water saturated with air as the pure ice melts. This situation would be expected at low temperatures where an impurity, e.g., water in normal heptane, is frozen but is sufficiently soluble in the major component to affect its freezing point $(182 \mathrm{~K})$; the liquid is saturated with the impurity over the entire range of fraction melted. [Experimental data seem to be non-existent, but the system oxygen-carbon dioxide could possibly be another example of such a system.]

The peritectic point of a binary system is an invariant point with four phases (including the vapor) in equilibrium; the equilibrium temperature remains unchanged as the amounts of the two solid phases and the liquid solution are changed on heating. In such systems or solids with more than one component (solid solutions), the self-diffusion rate is so slow compared with that in the liquid, that it is unlikely during the experimental period that there would be a true phase equilibrium $[16,17]$. In the extreme case where a frozen solid is uniform in composition and there is no diffusion in the solid, equilibrium temperature would remain unchanged at different fractions melted because the liquid composition would remain the same as that of the solid. In the real experimental case, there would be expected some segregation of impurities on freezing but very little diffusion in the solid.

Considering the above possibilities that would affect the triple point of oxygen, on most of which there is no direct quantitative information, it was 


\section{Journal of Research of the National Bureau of Standards}

decided to prepare as pure an oxygen sample as possible and to use extreme care in filling cells with the sample for triple point measurements. A small amount of impurity would have a relatively large effect on the small sample that was to be used. In the application of the method to obtain triple points for temperature standards, the sample should be sufficiently pure that the difference $\left(T_{0}-T\right)$ would be negligible. Although the oxygen samples were not expected to "behave ideally," the ideal solution theory was used as a guide in correlating the results.

\subsection{Calorimetric Cryostat}

The equilibrium temperatures were measured, at various known melted fractions of the oxygen samples, in an adiabatic cryostat that had been used previously for determination of heat capacities [18]. The miniature pressure cell of the oxygen sample was installed in place of the vessel that would contain the substance for heat-capacity measurements. Figure 1 shows schematically the general arrangement of the apparatus. The calorimetric apparatus was designed to provide as nearly adiabatic conditions as possible so that the observed equilibrium temperatures could be accurately correlated with the measured amounts of electrical energy that were introduced into the pressure-cell system. Briefly, the apparatus was designed as follows. The electrical leads (insulated $0.16 \mathrm{~mm}$ diameter copper wires) that entered the vacuum space of the apparatus through the hard-wax, "hermetic" lead seal of the terminal box were brought to the refrigerant temperature on the copper tempering ring. All tempering of electrical leads was done either by cementing them into close-fitting machined grooves (see fig. 1, "tempering ring," "ring lead control," and "thermometer-heater lead control") or by soldering them to the ends of copper strips cemented on "temperature-station" surfaces ("auxiliary isothermal shell" and pressure cell). To achieve adiabatic conditions, the leads were first heated on the floating copper ring lead-control close to the temperature of the thermometer-heater lead control. The leads that went to the pressurecell system were tempered next on the thermometer-heater lead control to the temperature of the auxiliary isothermal copper shell around the pressure cell. Before the leads went to the SPRT's, they were tempered on the auxiliary isothermal copper shell and then on the pressure cell. The insulation resistances between all leads and between the leads and their tempering surfaces were regularly checked to be $10^{9}$ ohms or larger. The temperatures of the adiabatic shield, thermometerheater lead control, and ring lead control were controlled by automatic adjustment of electrical power in the heaters wound on their surfaces, using appropriately placed differential thermocouples of constantan and Chromel-P wires. The heaters on the adiabatic shield were wound and cemented into close-fitting grooves machined into the shield. As mentioned above, the temperature of the floating ring lead-control was controlled relative to the temperature of the thermometer-heater lead control which was in turn controlled relative to the temperature of the auxiliary isothermal shell. The temperature of the adiabatic shield, that enclosed the pressure-cell system, was also controlled relative to the temperature of the auxiliary isothermal shell. The adiabatic shield, the thermometer-heater lead control, and the auxiliary isothermal shell were gold plated to reduce radiative heat transfer. During operation, the vacuum space was maintained at $10^{-3} \mathrm{~Pa}$ or less. With the double-dewar cooling system shown, temperatures of about $48 \mathrm{~K}$ to $49 \mathrm{~K}$ were reached by pumping on nitrogen in the inner dewar while liquid nitrogen at atmospheric pressure was in the outer dewar. (Hereafter, an oxygen sample, its pressure cell, auxiliary isothermal shell, tempering strips and the installed SPRT or SPRT's will be referred to as an oxygen sample system.)

\subsection{Energy Measurements}

The source of electrical energy for the heaters $(100 \Omega$ ) wound on the oxygen cells consisted of two $12 \mathrm{~V}$ lead storage batteries connected in parallel. The heater wire was an alloy (principally nickel and chromium) of low-temperature coefficient of resistance [19] so that the voltage readings across the heater would be nearly constant during current flow. All voltages [across the heater and across the reference resistor of known value (about $1 \Omega$ ) in series with the heater] were determined using a digital voltmeter with seven-digit readout. The range change feature of the digital voltmeter readily accommodated the 100 -fold voltage change across the heater and reference resistor. The time interval of heating, which was never less than $120 \mathrm{~s}$, was determined to within $\pm 0.01 \mathrm{~s}$ with a precision analog clock operated using the NBS 60 $\mathrm{Hz}$ frequency standard. The clock was operated synchronously with a switch that turned the current from a "dummy load" to the oxygen cell heater. (For details of the circuitry, see reference [20].) The voltages across the heater and the reference resistor were read alternately every $15 \mathrm{~s}$; the 


\section{Journal of Research of the National Bureau of Standards}

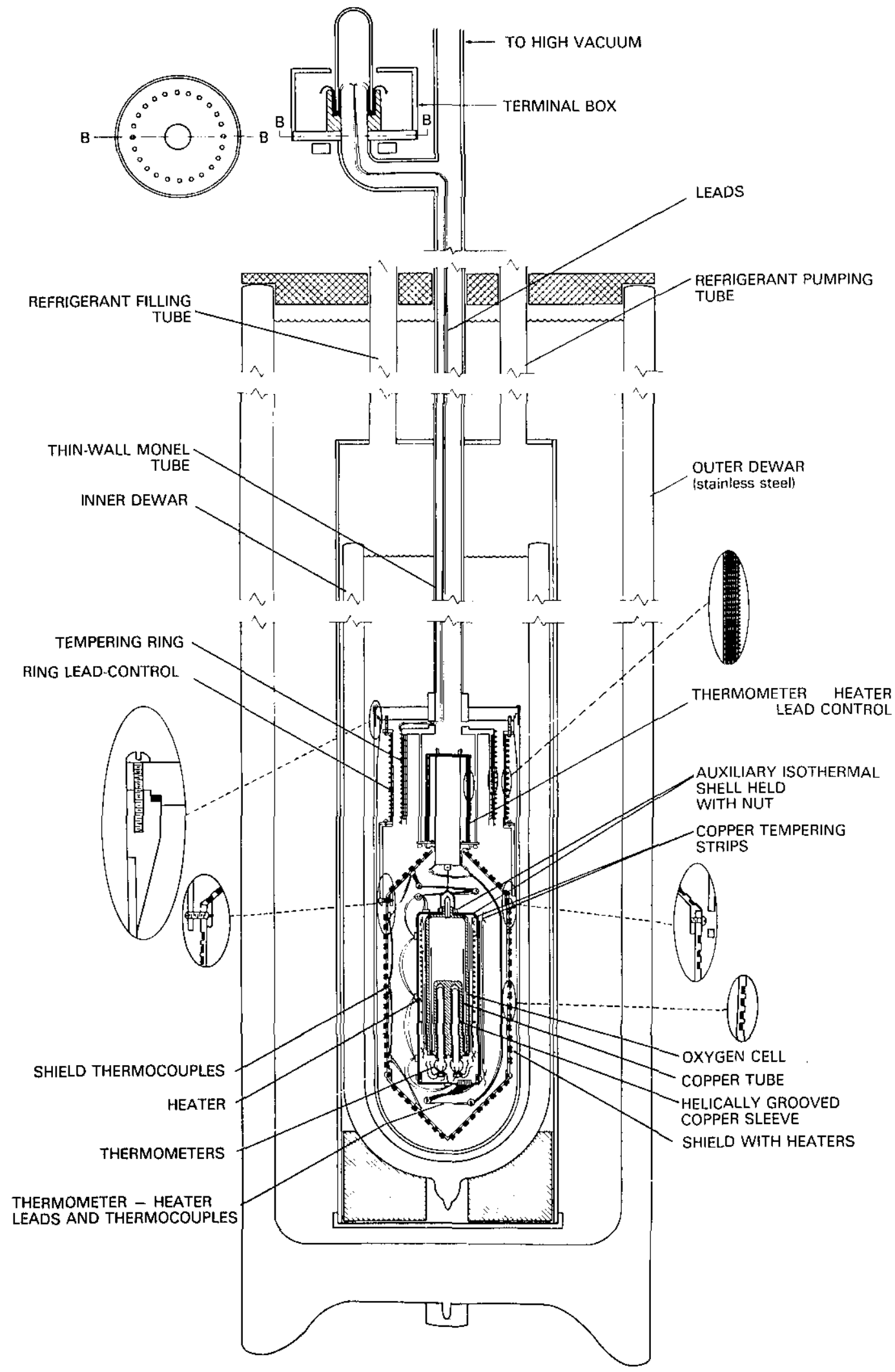

Figure 1-Schematic of adiabatic calorimetric apparatus shown with oxygen cell system PO-3 installed. 


\section{Journal of Research of the National Bureau of Standards}

readings were averaged to obtain the electric power that was introduced. The energy increments that were introduced were relatively large (30 to $300 \mathrm{~J}$ ) for the determination of the heat of fusion of the oxygen sample or the heat capacity of the oxygen-sample system, but only 3 to $20 \mathrm{~J}$ during measurements of the equilibrium temperatures at various small amounts of sample melted. The estimated accuracy of the electrical energy measure ments was about \pm 0.01 percent.

\subsection{Experimental Procedure}

The experimental procedure was very similar to that described for the investigation of argon triple point cells [6]. Briefly, with helium gas for heat exchange in the vacuum space of the cryostat, the inner and outer dewars were filled with liquid nitrogen. When the oxygen cell cooled to about 80 $\mathbf{K}$, the inner dewar was refilled with liquid nitrogen and pumped overnight using a high-capacity vacuum pump. During cooling, the liquid oxygen sample was found to supercool about $1 \mathrm{~K}$ before recalescence was observed. By morning, the oxygen sample had cooled to about 48 or $49 \mathrm{~K}$. The helium exchange gas was then removed and the vacuum space pumped out to a high vacuum (less than $10^{-3} \mathrm{~Pa}$ ), automatic temperature controls were switched on, and the temperatures of the adiabatic shield, of the floating ring lead-control, and of the themometer-heater lead control were controlled at the temperature of the auxiliary isothermal shell of the sample cell. Under these experimental conditions, a single filling of nitrogen in the inner dewar provided enough refrigeration to control the cryostat near the triple point of oxygen for about 80 hours.

After temperature equilibrium was established, the first series of measurements involved the determination of the heat capacity below the triple point, of the total heat of fusion, and of the heat capacity above the triple point. The procedure was as follows. Three heat-capacity "points" were obtained at successively increasing temperature below the triple point. The final temperature of the third heat-capacity point was arranged so that it would not be more than $1 \mathrm{~K}$ below the triple point. The first two values of heat capacity were used to estimate the amount of electrical energy required to heat within $1 \mathrm{~K}$ of the triple point. Electrical energy was then introduced continuously from the equilibrium temperature just below the triple point to just above it. The amount of energy to be introduced was estimated from the heat capacity and the approximate heat of fusion. After the equi- librium temperature was established just above the triple point, three heat-capacity points were obtained at successively increasing temperatures in the liquid phase of oxygen. The plot of these two sets of three heat-capacity points was used to determine the total heat of fusion and later the fraction of sample melted during the melting-point experiments.

The heat of fusion $L$ of the sample was calculated from the total heat $Q$ introduced from the temperature $T_{\mathrm{i}}$ just below the triple point to the temperature $T_{\mathrm{j}}$ just above it and the heat capacities in the two regions below and above the triple point according to the relation:

$$
L=Q-C_{\mathrm{s}}\left(T_{\mathrm{tp}}-T_{\mathrm{j}}\right)-C_{\mathrm{j}}\left(T_{\mathrm{j}}-T_{\mathrm{tp}}\right),
$$

where $C_{\mathrm{s}}$ is the heat capacity in the region of solid oxygen at temperature $\left(T_{\mathrm{i}}+T_{1 \mathrm{p}}\right) / 2, C_{1}$ is the heat capacity in the region of liquid oxygen at temperature $\left(T_{\mathrm{tp}}+T_{\mathrm{j}}\right) / 2$, and $T_{\mathrm{tp}}$ is the triple point temperature of oxygen. To determine the amount of electrical energy required to melt known amounts of oxygen, the sample was first cooled to a temperature about $1 \mathrm{~K}$ below the triple point and the equilibrium temperature was established under adiabatic conditions as previously described. After determining the equilibrium temperature $T_{1}$, the amount of heat $Q_{1}$ required to melt the desired initial fraction $F_{1}$ was calculated according to

$$
Q_{1}=F_{1} \times L+C_{\mathrm{s}}\left(T_{\mathrm{sp}}-T_{1}\right),
$$

where $C_{\mathrm{s}}$ is the heat capacity in the region of solid oxygen at temperature $\left(T_{1}+T_{\mathrm{tp}}\right) / 2$. After the equilibrium temperature was determined at fraction $F_{1}$ melted, energy $Q_{2}$ was added to obtain the equilibrium temperature at fraction $F_{2}$ melted according to

$$
Q_{2}=\left(F_{2}-F_{1}\right) L
$$

The energies for other fractions melted were determined in the same manner.

Depending upon the impurity concentration, a small fraction of sample may be already melted at the initial temperature $T_{\mathrm{i}}$ or $T_{\mathrm{l}}$ below the triple point. This "premelting" was calculated, and the adjustments were made wherever applicable, on the assumption that all of the impurities were in liquid solution (no solid solution) and the liquid solution to be ideal. The relation used was

$$
F_{\mathrm{p}}=55.40 x_{2} * /\left(T_{\mathrm{tp}}-T_{\mathrm{i}}\right),
$$




\section{Journal of Research of the National Bureau of Standards}

where $F_{\mathrm{p}}$ is the fraction premelted, $x_{2}{ }^{*}$ is the mole fraction impurity in the oxygen sample, 55.40 is $R T_{0}{ }^{2} / \Delta H$ given in eq (9), and $T_{\mathrm{i}}$ or $T_{1}$ is the initial temperature just below the triple point [20]. (Note: The symbols $T_{\mathrm{tp}}$ and $T_{0}$ for the triple point of pure oxygen will be used interchangeably.)

\section{Oxygen Samples}

Measurements were made on three oxygen samples in four sealed pressure cells. One sample was a commercially available "scientific-grade" oxygen stated by the supplier to be 99.999 percent pure with less than the following amounts of impurities in volume parts per million (vppm): 5 of argon, 3 of nitrogen, 0.5 of water, and 1 of carbon dioxide. Since the cost of chemical analysis was prohibitively high and since the material was unlikely to be used as our temperature standard, no further chemical analysis was made. This oxygen sample will be referred to as "commercial oxygen." The second oxygen sample was provided by the IMGC sealed in a pressure cell, as part of the Comite Consultatif de Thermométrie (CCT) sponsored program on the comparison of fixed points by means of sealed cells. This sample was also from a commercial source; its purity was stated to be 99.998 percent with impurities in vppm: 1.8 of nitrogen, 3.0 of argon, and 0.7 of methane [5]. The third oxygen sample was prepared by thermally decomposing potassium permanganate $\left(\mathrm{KMnO}_{4}\right)$. Extreme precautions were taken during the preparation to obtain a sample of the highest purity. This oxygen sample will be referred to as "prepared oxygen." The details of the procedure used in the preparation are given in the following section.

\subsection{Prepared Oxygen Sample}

In the preparation of oxygen by thermal decomposition of $\mathrm{KMnO}_{4}$, according to the process: $2 \mathrm{KMnO}_{4}+$ heat $\rightarrow \mathrm{MnO}_{2}+\mathrm{K}_{2} \mathrm{MnO}_{4}+\mathrm{O}_{2}$, copious amounts of fine powder are known to be produced that can be readily carried along with the stream of oxygen gas that is generated [21]. Figure 2 shows schematically the arrangement that was used to prepare the oxygen sample. The heating mantle around the $\mathrm{KMnO}_{4}$ sample flask contained an iron-constantan thermocouple which was used to monitor the heating temperature. Except for the valves, the valve manifold, and the high-pressure collection cylinder $\left(1000 \mathrm{~cm}^{3}\right)$, the entire system was constructed of borosilicate glass. The fine powder that was produced was confined in the generator by means of a column of tightly-packed, borosilicate glass-wool filter.

The $\mathrm{KMnO}_{4}$ sample (about $1500 \mathrm{~g}$ of "reagentgrade" material) was heated first to about $125^{\circ} \mathrm{C}$ and pumped at high vacuum for seven days. At the same time, the glass-wool filter and the glass parts were heated to about 100 to $150^{\circ} \mathrm{C}$ and pumped together with the $\mathrm{KMnO}_{4}$ sample. Earlier, the stainless-steel collection cylinder had been heated to $300^{\circ} \mathrm{C}$, pumped at high vacuum, filled with a small amount of the commercial scientific-grade oxygen, and evacuated repeatedly seven times over a period of one week. The high-vacuum line always included two liquid nitrogen traps in series to
Figure 2-Arrangement used for preparing oxygen by thermal decomposition of potassium permangante $\mathrm{KMnO}_{4}$.

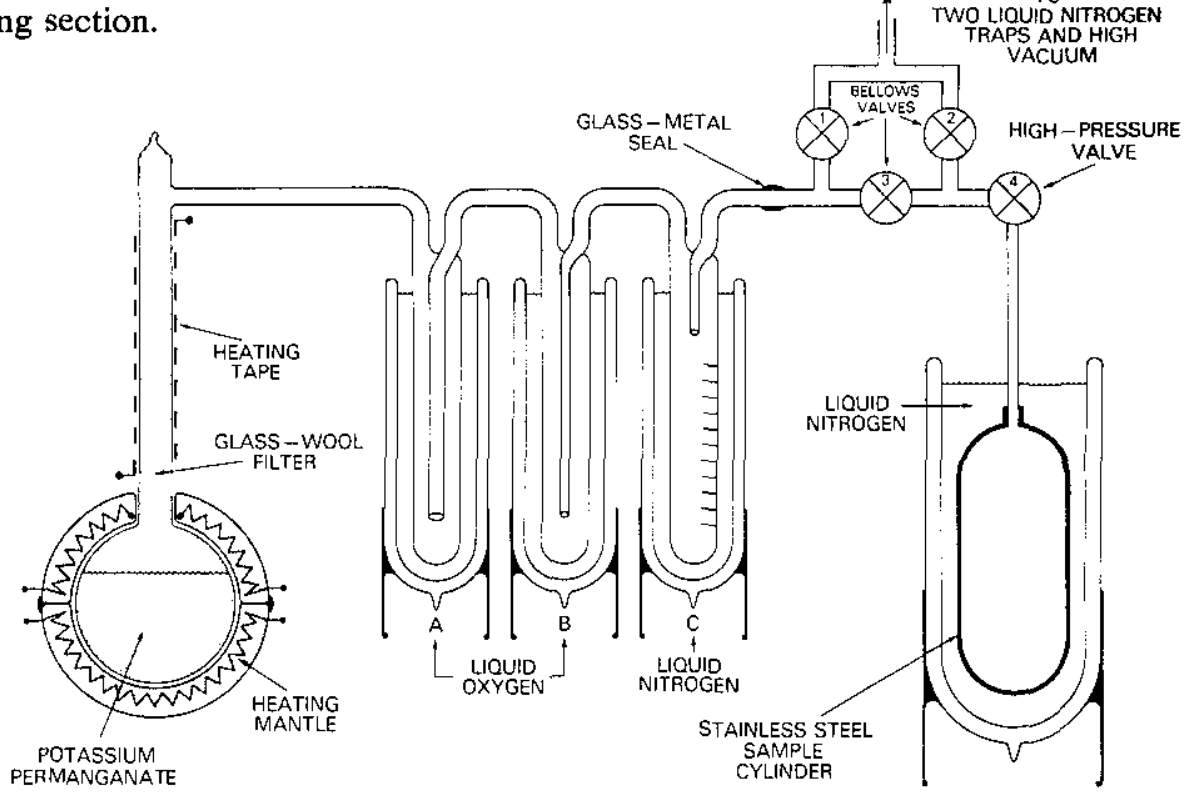


minimize any back diffusion of oil from the oil-diffusion vacuum pump. After the heating and pumping to remove as much of the moisture and air as possible from the oxygen-preparation system, dewars of liquid oxygen were placed around the drying traps $\mathrm{A}$ and $\mathrm{B}$ and a dewar of liquid nitrogen was placed around the graduated collection tube $\mathrm{C}$ which was used to measure the amount of liquid oxygen that would be transferred to the stainlesssteel cylinder. The $\mathrm{KMnO}_{4}$ sample was heated to about $210^{\circ} \mathrm{C}$, at which temperature liquid oxygen began to collect in the liquid-nitrogen cooled collection tube. When about $15 \mathrm{~cm}^{3}$ of liquid oxygen were collected, the heat in the mantle was turned off and the liquid oxygen that was collected was discarded by pumping. When the liquid oxygen was completely removed, the glass-wool filter and all glass parts were heated again to about 100 to $150{ }^{\circ} \mathrm{C}$ and pumped. In the meantime, the $\mathrm{KMnO}_{4}$ oxygen generator had cooled sufficiently to cease generating oxygen. The system was kept at about 100 to $150^{\circ} \mathrm{C}$ and was pumped overnight.

In the morning the generation of oxygen was resumed with liquid oxygen around the two drying traps (A and B) and liquid nitrogen around the collection tube (C). It was noted that, because of the insulating properties of the fine powder that was first formed adjacent to the heating mantle, the generation of oxygen started only after the thermocouple in the heating mantle indicated about $350^{\circ} \mathrm{C}$. After the oxygen began to collect the power in the heating mantle was reduced and a temperature of about $300^{\circ} \mathrm{C}$ was maintained. (Although the discarded liquid oxygen was "decidedly blue," the newly collected liquid oxygen appeared to be less blue. If small amounts of ozone had been collected in the discarded sample, the higher temperatures that were used during the second time would decompose further any ozone, if present [22].)

After about $110 \mathrm{~cm}^{3}$ of liquid sample were collected, the stainless steel cylinder was cooled in liquid nitrogen. The sample in the collection tube was then transferred to the cylinder by placing a dewar of liquid oxygen around the tube. Dewars of liquid oxygen were kept around the two drying traps during this transfer. Later, the pressure of oxygen sample $(78.5 \mathrm{~atm})$ in the stainless steel cylinder at ambient temperature indicated that about 3.5 moles were collected (about 75 percent yield based on the amount of $\mathrm{KMnO}_{4}$ used). No chemical analysis of the prepared oxygen was made but the very small range of the melting points of samples from the cylinder indicate that it is highly pure (see section 6). Two cells were later filled from the cylinder.

\section{Sealed Oxygen Cells}

The measurements of the triple point of oxygen were made in four miniature pressure cells of different designs. Three were designed and fabricated at NBS. These cells were hydraulically pressure tested with distilled water to $250 \mathrm{~atm}$ before filling with oxygen. The fourth cell was fabricated and filled with oxygen at IMGC. One of the NBS cells, which was filled with the commercially obtained oxygen sample, was fabricated from type 316 stainless steel pipe of $48.3 \mathrm{~mm}$ O.D. and $3.7 \mathrm{~mm}$ wall thickness. It was identical in construction to one of the cells designated as AR-NBS-7 which was used in the study of the triple point of argon (see figure 2 of reference [6]). The cell accommodated one thermometer and the sample volume was about 50 $\mathrm{cm}^{3}$. The extra large diameter was selected to determine whether future cells of the same diameter could be used with as many as seven SPRT's for calibration at the triple point of pure gases. The care that was exercised in its fabrication and in its filling with the oxygen sample was similar to that to be described for the following two NBS cells.

Two of the NBS cells, which were to contain the oxygen sample prepared from $\mathrm{KMnO}_{4}$, were smaller than the cell used to contain the commercial oxygen, particularly since there was only a limited amount of the prepared pure sample. These cells were fabricated from commercial type 304 stainless steel of $25.4 \mathrm{~mm}$ o.d. and $2.1 \mathrm{~mm}$ wall thickness. One of these two cells accommodated one thermometer and the sample volume was 20 $\mathrm{cm}^{3}$; the other cell accommodated three thermometers and its sample volume was $16 \mathrm{~cm}^{3}$. The shapes of these two cells were about the same as shown for the three-thermometer cell in figure 1 and for the one-thermometer cell in figure 3. Copper tubes were installed inside the cells to enhance thermal equilibrium. The wall thicknesses of the copper tubes were adjusted so that the condensed oxygen would completely surround the thermometer. Since the diameters of the structures containing the re-entrant wells for the one-thermometer cells (including the cell for the commercial oxygen) were smaller, the wall thicknesses of the copper tubes for the cells were greater than for the three-thermometer cell. Before these copper tubes were assembled inside the cells, they were heated in a vacuum furnace (about $10^{-4} \mathrm{~Pa}$ ) at $800^{\circ} \mathrm{C}$ for about 24 hours to remove any hydrogen or other gases that may be dissolved in the copper. The stainless steel joints were "heliarc" welded. 


\section{Journal of Research of the National Bureau of Standards}

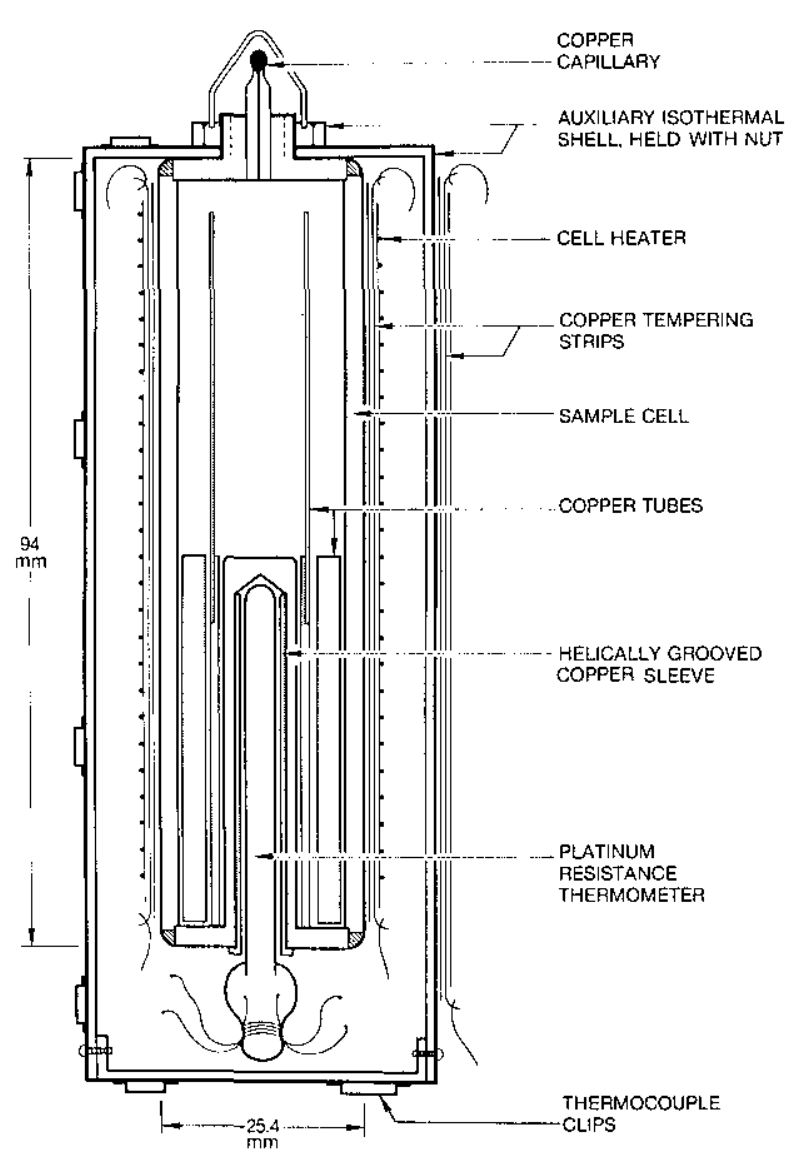

Figure 3-Oxygen cell system PO-1, shown for clearer view of construction. The cell PO-1 is similar to cell PO-3 shown in figure 1.

Extreme care and precautions were taken in cleaning and then filling the cells with the oxygen samples, since the design of the cells required these processes to be done through a copper or stainless steel capillary tube $(3.2 \mathrm{~mm}$ o.d. and $0.6 \mathrm{~mm}$ i.d.). The copper capillary was silver brazed first to the top lid of the stainless steel cell and thoroughly cleaned before welding the lid. The cell used with the commercial oxygen had a stainless steel capillary which was welded to the lid [6]. The cells were filled individually with sample at different times. Since the cells were first pressure-tested with distilled water before filling with oxygen, they were thoroughly dried by baking first at about $120^{\circ} \mathrm{C}$ inside a vacuum chamber for one week. During the week, the heated vacuum chamber containing the cell was filled several times with highpurity commercial oxygen and evacuated to displace any water vapor inside the cell. Care was taken to remove all of the water at the lower temperatures to avoid any possible reaction of water with the metal at the higher temperatures, forming the oxide and dissolving the hydrogen. After bak- ing for an additional two weeks at $300^{\circ} \mathrm{C}$ in vacuum, the cell was cooled under vacuum and back-filled with the high-purity commercial oxygen. Finally, the capillary filling tube of the cell was attached to a high-pressure manifold containing a stainless steel Bourdon-tube pressure gauge and an appropriate number (four) of valves for cleaning and filling the cell with sample. To the same manifold was attached the sample source with its separate high-pressure valve. The manifold, the Bourdon-tube gauge, and the cell were thoroughly evacuated (less than $10^{-4} \mathrm{~Pa}$ ) for several days with two liquid-nitrogen traps in series in the vacuum line. During this time, the cell was heated to about $400^{\circ} \mathrm{C}$ with a small tube-furnace. To avoid excessive oxidation of the cell, in particular the copper capillary tube, a gentle flow of argon or nitrogen was maintained inside the tube-furnace during the baking period. The manifold was occasionally heated using a "hot-air gun." After closing the valve to the vacuum system and after cooling the cell to ambient temperature, a small amount of the sample gas was introduced into the system and allowed to remain for several hours, after which the system was continuously evacuated overnight with the cell heated again to $400^{\circ} \mathrm{C}$. This process was repeated five times. After the fifth time, the valve to the vacuum line was closed and a small amount of the sample gas was introduced into the manifold system while the cell was at about $300^{\circ} \mathrm{C}$. It is expected that the copper surface and, to a lesser extent, the stainless steel surface were oxidized in the process. The purpose for oxidizing the surface was that the oxidized surface should be a barrier that would reduce the rate of future loss of sample oxygen through gradual oxidation of the metal surfaces. Following the oxidizing treatment, the cell was evacuated overnight and allowed to cool to the ambient temperature. Then, over a period of the next 10 days, the cell was purged 10 times by repeated filling with a small amount of the sample gas, allowing the gas to remain in the cell for a few hours, and then evacuating overnight. Finally, after the 10th purging operation, the cell was filled with sample to the desired pressure as read on the Bourdon-tube gauge and sealed by pinching the copper (or stainless steel) capillary tube flat over a length of about $2 \mathrm{~cm}$. The tube was cut at about the middle of the "flat" with a pair of pliers and tested immediately for gas leakage by immersing the cell in water. The flat of the stainless steel capillary tube was cut with a heliarc torch. The cut flats of the three cells, which were sealed at widely separated occasions, did not exhibit any gas leakage, nor did the adja- 


\section{Journal of Research of the National Bureau of Standards}

cent cut flats attached to the manifold. The cut edge of the flats and also the flats were covered with "soft solder" for added sealing and strength.

The cells were filled to sufficiently high pressures so that the heat of fusion of the sample in the cell would be comparable to or larger in magnitude than the heat capacity of the sample cell system (cell, sample, thermometer, auxiliary isothermal shell, copper tempering strips, and wires) and, therefore, the error contributed by the heat capacity in determining the amounts of sample melted would be negligible. The oxygen pressure in the cylinder of commercially obtained sample was 150 atm; hence, the $50 \mathrm{~cm}^{3}$ cell was filled directly to $113 \mathrm{~atm}$ at ambient temperature from the cylinder by controlling the valve to the manifold and observing the Bourdon-tube gauge. The heat of fusion of the sealed sample was $102 \mathrm{~J}$ and the heat capacity of this sample cell system was approximately $128 \mathrm{~J} / \mathrm{K}$ at $54.5 \mathrm{~K}$. The oxygen sample and this cell will be referred to as CO-7.

The desired filling pressures for the cells that would contain the oxygen sample prepared from $\mathrm{KMnO}_{4}$ were higher than the 78.5 atm pressure of the sample in the storage cylinder. The one-thermometer cell was filled to $100 \mathrm{~atm}$ at ambient temperature by first cooling the cell nearly to the temperature of a Dry Ice-ethyl alcohol mixture and then introducing the sample from the storage cylinder. The heat of fusion of the sealed sample was 35 $J$ and the heat capacity of this sample cell system was approximately $38 \mathrm{~J} / \mathrm{K}$ at $54.5 \mathrm{~K}$. This specimen of prepared oxygen and the cell will be referred to as PO-1.

The three-thermometer cell was filled to $163 \mathrm{~atm}$ at ambient temperature by first cooling the cell to the temperature of liquid nitrogen and then introducing the oxygen sample from the storage cylinder for a measured period of a few minutes through a flow control valve. After closing the control valve, the sample cell was allowed to warm to the ambient temperature and the pressure read on the Bourdon-tube gauge. On the basis of this pressure reading and the period of time the flow control valve was open, an estimate was made of the time that would be needed for the second filling, at the same flow condition, to fill the cell to the desired pressure. The heat of fusion of the sealed sample was $53 \mathrm{~J}$ and the heat capacity of this sample cell system was approximately $35 \mathrm{~J} / \mathrm{K}$ at $54.5 \mathrm{~K}$. This specimen of oxygen and the cell will be referred to as PO-3.

The thermometer wells of the three pressure cells that were made at NBS were designed to be about $1 \mathrm{~mm}$ larger in diameter than the typical outer diameter of capsule-type SPRT's to accommodate copper sleeves that closely fitted the well and the capsule SPRT. Widely spaced helical grooves were machined into the outer surface of the sleeves to vent air, so that the SPRT could be easily installed or removed from the well withoutcausing possible harm to the SPRT. To enhance heat transfer between the parts, a thin film of stopcock grease was used on surfaces that were in contact.

The cells were designed to accommodate the auxiliary isothermal shells which were held in place at the top by nuts (see figs. 1 and 3). The auxiliary isothermal shell, made of copper, served to protect the SPRT from stray thermal radiation and also temper the electrical leads before they were tempered on the cell itself. During the measurement process, the shell provided an isothermal surface for adiabatic control and thus reduced thermal gradients in the cell. A thin film of stopcock grease was applied to the screw threads and the surfaces in contact to enhance heat transfer. The auxiliary isothermal shell had clips for differential thermocouples for controlling the temperature of the adiabatic shield. The shell for the oxygen cell CO-7 with one SPRT, as well as the cell itself, had six copper strips (four for the SPRT's leads and two for the heater leads) for tempering the electrical leads. Lens paper was used for electrically insulating the copper strips from the surface on which they were cemented for thermal contact. Similarly, the oxygen cell PO-1 and its auxiliary isothermal shell had six copper strips each for tempering the electrical leads. The electrical insulation in this case was Mylar film that was about $0.01 \mathrm{~mm}$ thick. The oxygen cell PO-3 with wells for three SPRT's had 10 copper tempering strips cemented on it and on its auxiliary isothermal shell. Mylar film was used for electrical insulation.

The fourth cell was constructed and filled with oxygen at IMGC [5]. As previously mentioned, this cell is one of the reference cells that is being circulated among different national laboratories as part of the program on International Intercomparison of Fixed Points by Means of Sealed Cells sponsored by the CCT. The cell design is indicated as Model C by IMGC [5]. It has a re-entrant well that can accommodate a tapered copper plug which is large enough for installing three SPRT's. The heat of fusion of the sample was $47 \mathrm{~J}$ and the heat capacity of the assembled sample cell system was $40 \mathrm{~J} / \mathrm{K}$ at $54.5 \mathrm{~K}$. This cell with its oxygen sample will be referred to as IMGC- $80_{2}$. 


\section{Journal of Research of the National Bureau of Standards}

In order to accommodate three SPRT's in the IMGC- $8 \mathrm{O}_{2}$ cell, a small groove was first machined along the taper on the plug in which the three SPRT's were to be installed. The groove vented air so that the three SPRT's could be safely handled with the cell. A special auxiliary isothermal shell was constructed for the cell and 10 copper tempering strips were attached for measurements with three SPRT's, similar to cell PO-3.

The heater for introducing known amounts of electrical energy into the oxygen sample system was wound directly over the copper tempering strips on the cylindrical surface of all four cells using glass fiber insulated heater wire. In the earlier tests with sealed argon cells [6], the location of the heater did not seem to affect the measurement; however, the heater was wound mostly on the upper half of CO-7, and PO-3 cells to drive any condensate to the bottom of the cell. On cells PO-1 and IMGC- $80_{2}$, the heater was evenly distributed over the cylindrical surface in order to determine whether more even distribution of heating would reduce the equilibrium time. No significant difference in equilibrium time or in the measurements was observed among the cells.

\section{Thermometry}

\subsection{Thermometers and Temperature Scales}

A total of six capsule SPRT's with NBS-IPTS-68 calibrations [23] was used. Three of the SPRT's $(1812279,1812282$, and 1812284) were those furnished to the National Physical Laboratory (NPL, U.K.) for the international comparison of temperature scales below $0{ }^{\circ} \mathrm{C}$ [24]. As a result of that comparison, these three SPRT's have calibrations also on the NPL-IPTS-68 [24]. These SPRT's were calibrated three times before shipping to the NPL and twice after they were returned. These three SPRT's will be referred to as the international SPRT's. In addition, the "standard thermometer" 1728839 that was employed for comparison of the temperature scales at the NPL had also been calibrated on August 22, 1969 in terms of the NBSIPTS-68. The other three SPRT's (1774092, 1774095 , and 1842382) have been calibrated twice; they have been used only at NBS.

The history of calibrations of the six SPRT's at $54.361 \mathrm{~K}$ is summarized in table 1 by comparing their resistance ratios for the temperature, relative to that of the latest calibration, and converting the differences to corresponding temperature values. A similar comparison of calibration for $83.8 \mathrm{~K}$ of the same SPRT's was described previously in the measurements of the argon triple point [6]. To be consistent with the comparison of calibrations presented in the earlier argon work [6], wherever the value of the resistance ratio $W$ at $54.361 \mathrm{~K}$ was smaller than the value for the latest calibration, the corresponding value of temperature difference is given in the table with a minus sign. However, in using such calibrations, the value of temperaturethat is calculated for a given observed value of $W$ would actually be larger.

The relatively large differences for $8 / 29 / 74$ and earlier calibration for SPRT's 1812279, 1812282, and 1812284, which among themselves agree closely, suggest possibly that a small change occurred in the calibration between the times these SPRT's were shipped to the NPL and returned. Therefore, there is an uncertainly of about $0.1 \mathrm{mK}$ in the comparison of the IPTS-68 maintained at the NBS [23] and that at NPL [24]. As mentioned earlier, the other three SPRT's 1774092, 1774095, and 1842382 have been used only at the NBS. The agreement in the calibrations for SPRT 1774092 and 1774095, although performed six years apart, approach the precision of single calibrations around $54.361 \mathrm{~K}$. The difference in the calibrations for SPRT 1842382 is larger than that which would be expected for normal calibrations. Nevertheless, table 1 shows that the calibrations on all six SPRT's are highly consistent and reproducible over a number of years and that capsule SPRT's when used with care, can retain their calibration over many years. This outstanding stability is further supported by the consistency of values of triple points of argon obtained earlier [6] with the same six SPRT's and by the consistency of values of triple points of oxygen to be presented later in this paper. This indicates also that the SPRT reference standards that maintain the NBS-IPTS-68 [23] are stable, unless, of course, all SPRT's that are involved in this comparison drift at the same rate, which is unlikely.

The outstanding stability of SPRT's and the consistency of calibrations of SPRT's that can be realized are demonstrated additionally by the results obtained at the NPL on the oxygen triple point using SPRT 1728839 with NBS-IPTS-68 calibration [4]. The SPRT 1728839 represented also the NPL-IPTS-68 for the international comparison of SPRT calibrations [24]. The value $(54.3615 \mathrm{~K})$ obtained on the NBS-IPTS-68 for the oxygen triple point at the NPL using SPRT 1728839 [4] is in perfect agreement with the differences found by comparing SPRT's between the NPL-IPTS-68 (represented by SPRT 1728839) and the NBS- 
Table 1. Calibration history of thermometers (calibration in terms of the NBS-IPTS-68) a.

\begin{tabular}{|c|c|c|c|c|c|c|}
\hline \multirow[t]{3}{*}{ Thermometer } & \multicolumn{5}{|c|}{$\begin{array}{l}\text { Calibration Date and } \\
\text { Deviation at } 54.361 \mathrm{~K} \\
\text { from the Latest Calibration }\end{array}$} & \multirow{3}{*}{$\begin{array}{c}\begin{array}{c}\text { Deviation } \\
\text { from the }\end{array} \\
\text { NPL-IPTS-68c }\end{array}$} \\
\hline & & & $\mathrm{mK}$ & & & \\
\hline & $2 / 2 / 77^{b}$ & $2 / 1 / 71$ & & & & \\
\hline 1774092 & 0 & +0.032 & & & & \\
\hline \multirow[t]{2}{*}{1774095} & 0 & -0.016 & & & & \\
\hline & $6 / 22 / 76^{b}$ & $3 / 18 / 76$ & $8 / 29 / 74^{d}$ & $8 / 9 / 74^{d}$ & $7 / 18 / 74$ & \\
\hline 1812279 & 0 & -0.051 & -0.116 & -0.126 & -0.076 & $+0.6^{c}$ \\
\hline 1812282 & 0 & -0.043 & -0.110 & -0.100 & -0.083 & $+0.5^{e}$ \\
\hline \multirow[t]{2}{*}{1812284} & 0 & -0.055 & -0.149 & -0.154 & -0.074 & $+0.6^{e}$ \\
\hline & $7 / 22 / 81^{b}$ & $1 / 10 / 78$ & & & & \\
\hline 1842382 & 0 & -0.080 & & & & \\
\hline
\end{tabular}

"NBS-IPTS-68 is a "wire scale"; see reference [23].

"Latest calibration; hence, zero deviation is shown.

c From reference [24].

d These calibrations were submitted to the NPL for the international comparison of temperature scales [24]. The average of these two calibrations was compared with NPL-IPTS-68.

"The positive figures indicate that the triple point of oxygen as realized at the NPL is "hotter" than the value $54.361 \mathrm{~K}$ on the NBS-IPTS-68. Based on W(54.361 K) of the NPL-IPTS-68 and average NBS-IPTS-68 indicated as $\mathrm{d}$ above, the average deviation for the three SPRT's corresponds to $+0.588 \mathrm{mK}$.

IPTS-68 [23] (represented by SPRT's 1812279, 1812282 , and 1812284); see table 1 for the differences of the latter three SPRT's. The NBS calibration date and the date of NPL measurement of the oxygen triple point with SPRT 1728839 are almost five years apart [4]. (Note: the SPRT 1728839 was calibrated originally in terms of the NBS-1955 scale. Later, the scale was converted to NBSIPTS-68 in accordance with the published differences $[25,26]$.)

For measurements in the oxygen triple-point cells, the capsule SPRT's were installed as shown in figures 1 and 3 . To obtain the resistance ratio $W$ (i.e., the resistance at the oxygen triple point to that at $0^{\circ} \mathrm{C}$ ), the capsule SPRT's were installed in special holders [26] for resistance measurements at the triple point of water (TP). (For the description of the procedure for converting the observed resistance at the TP to that at $0^{\circ} \mathrm{C}$, see reference [27].) All analyses of measurements were made in terms of the resistance ratio $W$ with zero thermometer current. The conversion to values of temperature (NBS-IPTS-68) was made only at the end of the analysis for presentation of the results.

\subsection{Measurement of Thermometer Resistance}

A Guildline Model 9975 current comparator bridge [28] was used for measuring the resistance of the SPRT's. In conjunction with the bridge, a $10 \Omega$ Rosa-type reference resistor [29] and a stripchart recorder were used. The reference resistor was thermostated at about $30^{\circ} \mathrm{C}$, near the maximum of its resistance versus temperature curve. On the basis of the indications of an industrial-type $100 \Omega$ platinum resistance thermometer installed in the thermometer well of the reference resistor, the variations in the temperature of the reference resistor were not greater than $\pm 1 \mathrm{mK}$. The amplifiers of both the bridge and the recorder were adjusted so that $1 \mathrm{~mm}$ on the recorder chart corresponded to about $3 \times 10^{-7} \Omega$. The recorder tracings were estimated to about $0.3 \mathrm{~mm}$ so that the readings of the measurement system would correspond closely to $1 \times 10^{-7} \Omega$. During measurements, the bridge and the strip-chart recorder provided a continuous record of the temperature of the oxygen cell. The strip-chart recorder was run always at the relatively slow speed of $5 \mathrm{~cm}$ per hour so that the observed "equilibrium tracings" would indeed be equilibrium temperature tracings. The chart 


\section{Journal of Research of the National Bureau of Standards}

recorder was operated continuously so that it would also serve as a clock for regulating the measurement process.

In using the current comparator brìdge, there was some concern regarding the manner in which the reference resistor might change in resistance with current. For the determination of the resistance ratio $W$, measurements at the triple points of water and oxygen are required which involve nearly 11-fold current variation in the reference resistor (from about 3.6 to $0.33 \mathrm{~mA}$, respectively, with $\sqrt{2} \mathrm{~mA}$ through the SPRT). However, since the temperature of the reference resistor was controlled near the maximum of its resistance versus temperature curve, and since the resistor was immersed directly in oil, the effect of small power variations on its resistance at the low power that was used was considered negligible.

To minimize the effect on the resistance ratio caused by the slow drift in the resistance of the reference resistor, the resistances of the SPRT's at the triple point of water, $R(\mathrm{TP})$, were determined just prior to or very soon after the measurements at the triple point of oxygen. The values of $R(\mathrm{TP})$ were plotted as a function of the date for each SPRT. Usually the observed value of $R$ (TP) was used for calculating the resistance ratio; but, whenever there was a significant difference in the successive values of $R(\mathrm{TP})$, the value of $R(\mathrm{TP})$ was selected from the plot at the date that corresponded to the date at which the observations at the triple point of oxygen were made.

To make negligible the error that would arise from variations in self-heating in the SPRT's, measurements were made at two currents ( 1 and $\sqrt{2}$ $\mathrm{mA}$ ) and the value at zero power (zero current) was obtained by linear extrapolation of the power dissipated in the SPRT. The validity of this linear extrapolation was checked with every new installation of the oxygen triple-point cell in the calorimetric cryostat by measurements at three currents (1, $\sqrt{2}$, and $0.3 \sqrt{2}$ or $3 \mathrm{~mA}$ ). The self-heating values of the SPRT's, obtained from the measurements at 1 and $\sqrt{2} \mathrm{~mA}$, served as a check during measurements and in the analysis of the measurement data, since the values for a given SPRT should not show large differences from one measurement to another.

The procedure for measuring thermometer resistance was to determine the zero of the measurement system on the strip-chart recorder during the period the sample was being heated and the subsequent 10 to 20 minutes after the heating while the sample system was reaching temperature equilibrium. Actually, the zero was determined by sim- ply switching the bridge current off, following the completion of the measurement of the equilibrium temperature. Hence, during this period, the thermometer connections and the settings on the amplifier switches of the bridge (galvanometer sensitivity switch for the bridge) and the strip-chart recorder were undisturbed and at the same positions at which the equilibrium readings were obtained, so that any "offset" would be included as part of the zero. After the zero of the measurement system was satisfactorily determined, the thermometer resistance at the new equilibrium temperature was then measured. The equilibrium temperatures were observed for 30 minutes to an hour or longer for each SPRT, depending upon the position in the measurement sequence in a particuIar "run." (A run represents a freezing of the oxygen samples and the series of equilibrium temperature measurements at different fractions melted.) Except where the sample was less than about 15 percent or between about 85 and 100 percent melted, the oxygen sample system reached temperature equilibrium after heating within about 15 to 20 minutes. The usual practice was to record for at least 12 to 18 minutes ( 1 to $1.5 \mathrm{~cm}$ of chart record) of readings that were essentially constant near the zero of the measurement system at $1 \mathrm{~mA}$ and then at $\sqrt{2} \mathrm{~mA}$, plus the determination of the sensitivity at these two currents. The sensitivity was determined by reducing the bridge dial reading 50 units (least significant units) which corresponded to a change of about $15 \mathrm{~cm}$ in the recorder pen position or about $50 \mu \Omega$. (Note: The recorder chart width was $25 \mathrm{~cm}$. For convenience, the zero tracing was located toward the right of the chart around the $20-\mathrm{cm}$ position and the recorder was connected to the bridge so that when the bridge readings were reduced the recorder pen would deflect to the left. With this arrangement, the recorder tracing gives the "temperature versus time curve" which can be copied directly.) The recorder tracings for determining the sensitivity corresponded usually to 5 to 10 minutes in length. Since the sensitivity should be nearly constant and also the zero should be at approximately the same location on the strip chart, they served as checks on the proper performance of the measurement system.

After the completion of the equilibrium readings on an SPRT, the thermometer current was switched off before introducing electrical energy into the oxygen sample system for the next fraction melted. If the oxygen sample system contained three SPRT's, equilibrium measurements on the other SPRT's were successively made. Since the 
complete measurements with three SPRT's required two to three hours or longer, occasionally the measurements on the first of the three SPRT's were repeated to check the state of equilibrium of the oxygen sample system. Any differences were usually within $0.01 \mathrm{mK}$; however, differences as large as $0.03 \mathrm{mK}$ occurred below about 15 percent and between about 85 and 100 percent melted. Often it was convenient to allow the system to reach equilibrium overnight after heating. Unless the adiabatic control conditions changed drastically overnight, tests showed that the readings of the next morning were within 0.01 or $0.02 \mathrm{mK}$ of thoseof the previous day. Again, larger changes, as much as $0.05 \mathrm{mK}$, were observed below about 15 percent and between about 85 and 100 percent melted.

\section{Results and Discussions}

A total of 12 sets of equilibrium temperature measurements was made at different ratios of liquid to solid oxygen with six SPRT's using the four oxygen cells and two cryostats. (A set of measurements with an SPRT is the observations of all runs with the SPRT and cell for a given installation in the cryostat. If the cell were remounted in the cryostat, the new measurements with the SPRT were counted in another set. A cell with three SPRT's can yield three sets of equilibrium temperature measurements for the same installation.) SPRT 1774095 was used with oxygen cell CO-7 contain- ing the commercial oxygen; this SPRT was also used with oxygen cell PO-1 containing the prepared oxygen. In addition, SPRT 1774095 was used together with SPRT's 1774092 and 1842382 with oxygen cell PO-3 containing the prepared oxygen. SPRT 1812282 was used with oxygen cell PO-1 and also used together with SPRT's 1812279 and 1812284 with oxygen cell PO-3. The three international SPRT's 1812279, 1812282, and 1812284 were also used together in oxygen cell IMGC- $8 \mathrm{O}_{2}$. The measurements of SPRT 1774095 with oxygen cell CO-7 was made in cryostat " $\mathrm{S}$ "; the other measurements were all made in cryostat "T." For economy of space, representative sets of measurements are shown for each of the oxygen cells in figures $4,5,6$, and 7 by plotting $W(T)$ versus the fraction melted $F$ and $W(T)$ versus the reciprocal of fraction melted $1 / F$ for the measurements of SPRT 1774095 with cells CO-7, PO-1, and PO-3 and measurements of SPRT 1812282 with cell IMGC- $80_{2}$. Since SPRT 1774095 was not used with cell IMGC- $80_{2}$, the results with SPRT 1812282 were selected because the SPRT was also used with cells PO-1 and PO-3. Some of the observations given for the $W(T)$ versus $1 / F$ plot are not shown for the $W(T)$ versus $F$ plot. One vertical division in $W(T)$, which corresponds to $\Delta W=0.000001$, is equivalent to $0.256 \mathrm{mK}$. [Note: the results obtained in this investigation will be expressed to the nearest $0.001 \mathrm{mK}$. For a given assemblage of equilibrium temperature tracings for two currents (see section 5.2), the SPRT resistance at zero current that was calculated was estimated to be precise to \pm 0.001 to $\pm 0.002 \mathrm{mK}$.]
FRACTION MELTED

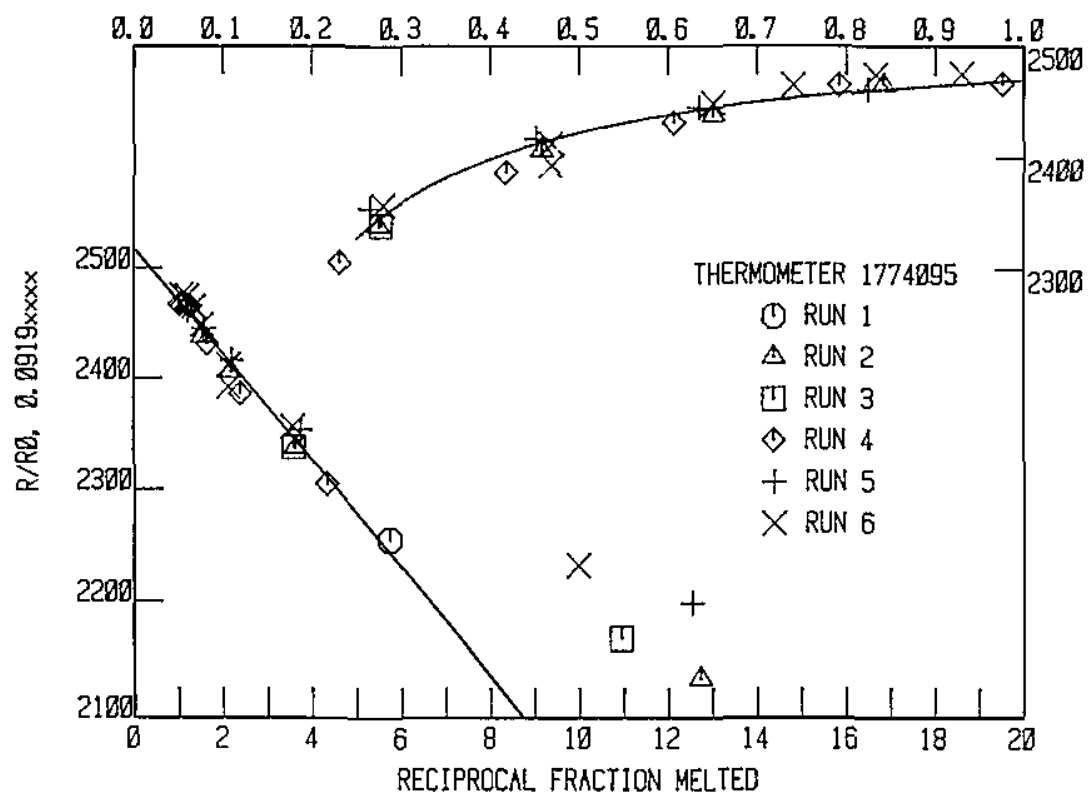

Figure 4-Values of resistance ratios (W) at equilibrium temperatures of various amounts of the commercial oxygen sample melted; for thermometer 1774095, cell CO-7, cryostat "S." The upper part of the figure shows values of $W$ (scale on the right) at various fractions of the sample melted. The lower part shows the same values of $W$ (scale on the left) plotted in terms of the reciprocals of the fractions melted. The solid curves represent the results of least-squares fitting of eq (9) to the data. 


\section{Journal of Research of the National Bureau of Standards}

FRACTION MELTED

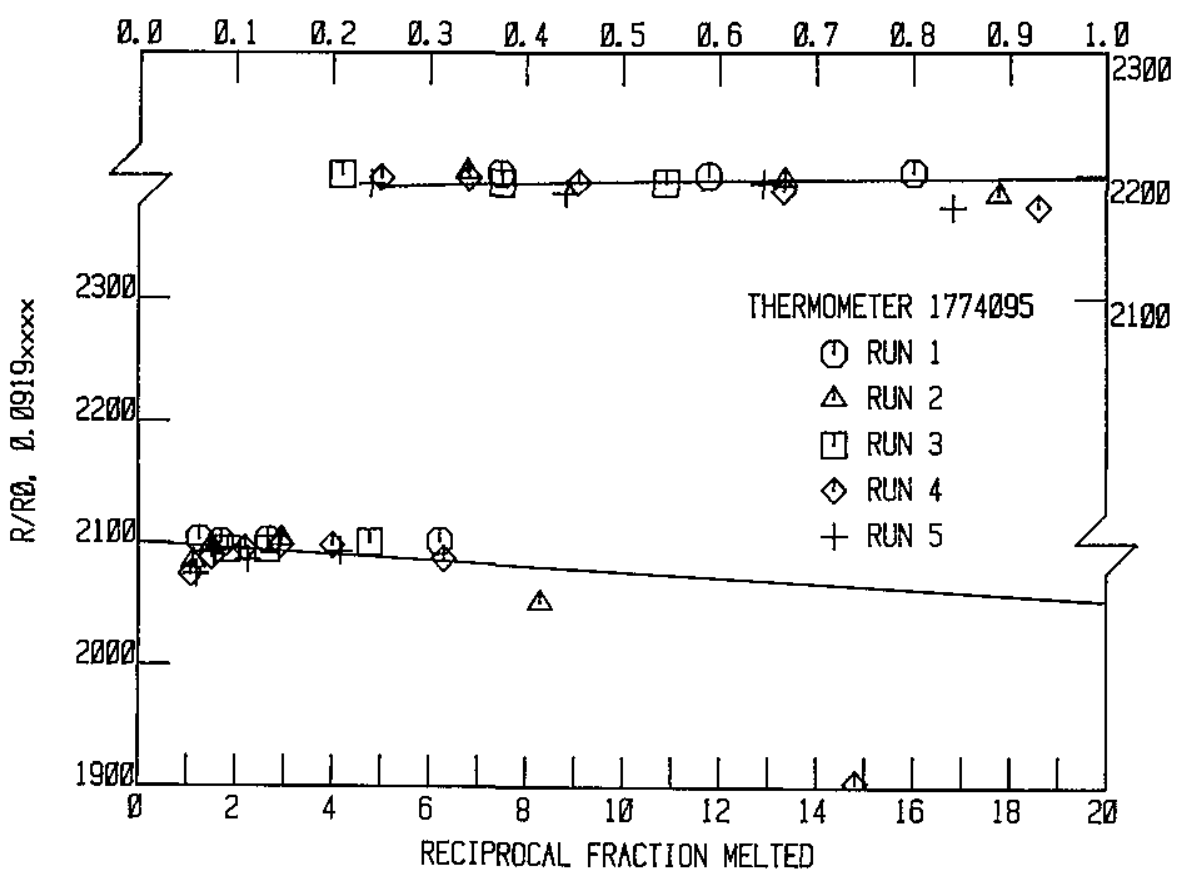

Figure 5-Values of resistance ratios $(W)$ at equilibrium temperatures of various amounts of the prepared oxygen sample melted; for thermometer 1774095, cell PO-1, cryostat " $T$." (See fig. 4 for explanation of the plot.)

FRACTION MELTED

Figure 6-Values of resistance ratios $(W)$ at equilibrium temperatures of various amounts of the prepared oxygen sample melted; for thermometer 1774095 , cell PO-3, cryostat " $T$." (See fig. 4 for explanation of the plot.)

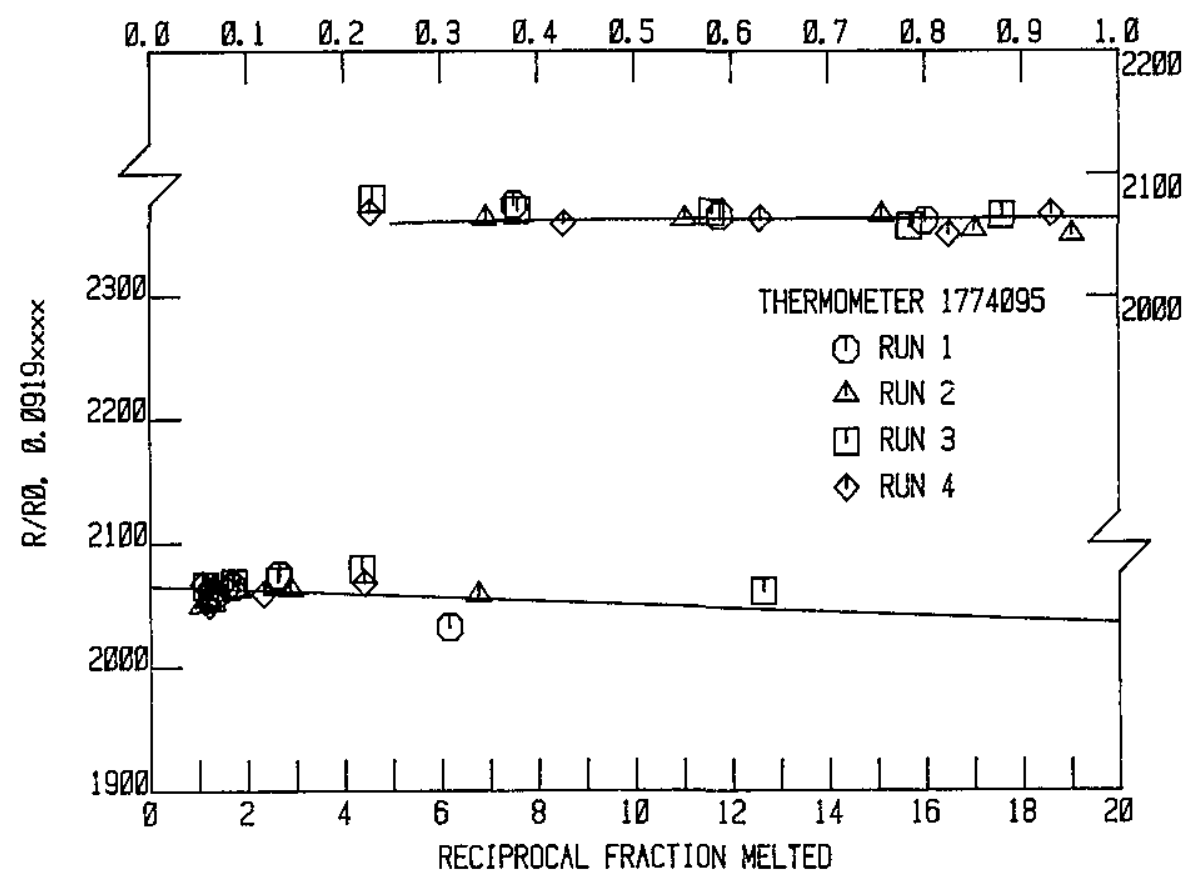




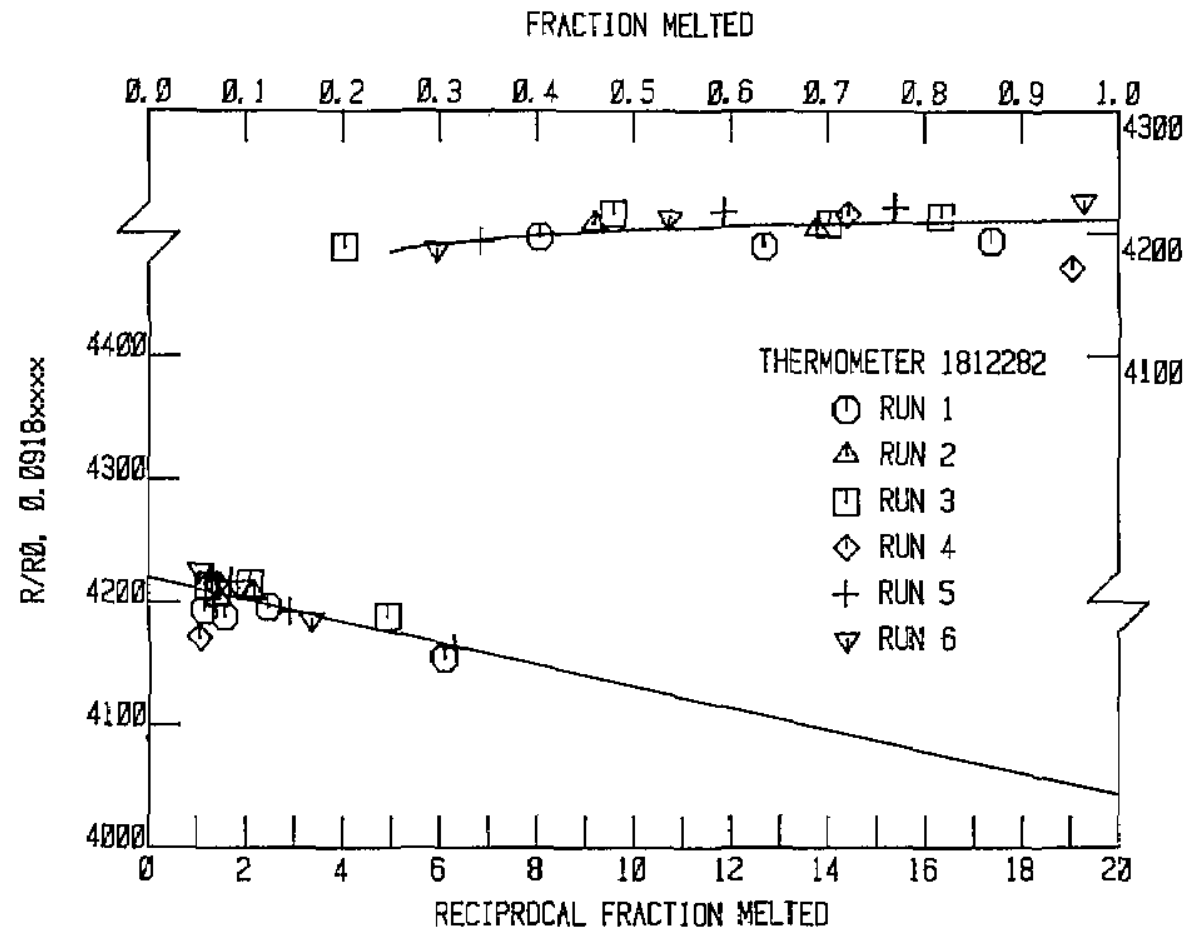

Figure 7-Values of resistance ra. tios $(W)$ at equilibrium temperatures of various amounts of the commercial oxygen sample melted; thermometer 1812282 , cell IMGC-802, cryostat " $T$." (See fig. 4 for explanation of the plot.)
In the figures, the straight line associated with the $W(T)$ versus $1 / F$ plot was obtained by fitting the observations by the least-squares method to the linear relation given by eq (9). The curve associated with the $W(T)$ versus $F$ plot was calculated by employing with eq (9) the values for the slope $\left(55.40 x_{2}^{*}\right)$ and $W\left(T_{0}\right)$ ("triple point of pure oxygen") obtained by the least-squares method for the set of measurements on the sample. The results are apparently in good agreement with the idealized eq (9). The deviations that are shown most likely originate from the experimental process, where thermal equilibrium for the system was not awaited long enough or from lack of complete adiabatic condition. The least-squares values of the slopes give for the mole-fraction impurity $x_{2}^{*}$ of eq (9) $1.2 \times 10^{-6}$, $8.2 \times 10^{-8}, 7.0 \times 10^{-8}$, and $4.1 \times 10^{-7}$ for cells $\mathrm{CO}-7$, $\mathrm{PO}-1, \mathrm{PO}-3$, and IMGC-80, The slopes of the figures correspond to $\Delta W / \Delta(1 / F)$. For eq (9), the conversion $\Delta T / \Delta(1 / F)=256 \times \Delta W / \Delta(1 / F)$ was made at $54.4 \mathrm{~K}$.] Compared with the stated amounts of impurities, the values seem to give rather high purity for the commercial samples, by a factor of 10 or more, possibly because of the deviation from true phase equilibrium or of the narrow separation of the liquidus and solidus curves in the case of the oxygen-argon system. The purity of the prepared oxygen sample is at present unknown except that it was prepared with extreme care.
Some of the equilibrium temperatures above about 0.8 fraction melted are shown to be relatively low. Also, the observed equilibrium temperatures at low fraction melted (less than about 0.1 ) show large deviations in terms of the high degree of agreement in the range 0.1 to 0.8 fraction melted. A plausible explanation for part of this is attributed to the lack of complete adiabatic condition. In the region above about 0.8 fraction melted, the equilibrium temperature can be made relatively higher or lower depending upon the direction of heat transfer relative to the oxygen cell system. Where the fraction melted is small or large, the amount of liquid to solid interface is relatively small. The adjustment to temperature gradients can occur more rapidly when there is a well-distributed large liquid to solid interface; small heat loss or gain of the oxygen cell system can be accommodated by melting or freezing. However, at small amounts of liquid to solid interface the accommodation becomes less and the thermometer begins to indicate more temperature gradients and more of what is happening to the oxygen cell system, because the sample, as well as the cell, have relatively low thermal conductivity. The degree of deviation from the true equilibrium temperature depends upon the quality of adiabatic condition and the location of the thermometer where temperature gradients exist. However, the observed deviations shown are small in 


\section{Journal of Research of the National Bureau of Standards}

terms of the final mean value for the oxygen triple point.

Table 2 summarizes all of the sets of oxygen triple point measurements with the six SPRT's. The values of $W(T)$ tabulated are those at $1 / F=1$ obtained by the method of least squares mentioned above. The values of temperatures on the NBS-
IPTS-68 scale are based on the latest calibration (see table 1). The values of temperatures on the NPL-IPTS-68 for the international SPRT's are based on the calibrations obtained at the time of the international comparison of temperature scales [24]. The values of temperatures on the NPLIPTS-68 for SPRT's 1774092, 1774095, and

Table 2. Measurements at the triple point of oxygen.

Oxygen Cells: CO-7, commercial oxygen, sealed April 1980

PO-1, prepared oxygen, sealed February 1983

PO-3, prepared oxygen, sealed July 1983

IMGC- $80_{2}$, commercial oxygen, sealed November 1978

SPRT

Oxygen Triple Point Cell

\begin{tabular}{|c|c|c|c|}
\hline $\mathrm{CO}-7$ & PO-1 & PO-3 & IMGC-80, \\
\hline$W, 1 / F=1.00^{\mathrm{a}}$ & $W, 1 / F=1.00^{\mathrm{a}}$ & $W, 1 / F=1.00^{\mathrm{a}}$ & $W, 1 / F=1.00^{\mathrm{a}}$ \\
\hline K, NBS-IPTS-68 & K, NBS-IPTS-68 & K, NBS-IPTS-68 & K, NBS-IPTS-68 \\
\hline K, NPL-IPTS-68 & $\underline{K}, \underline{\text { NPL-IPTS-68 }}$ & $\underline{K}$, NPL-IPTS-68 & K, NPL-IPTS-68 \\
\hline
\end{tabular}

1774092

1774095

0.09192447

54.362366

$54.361904^{f}$

1812279

1812282

1812284

1842382 $0.09183956^{\mathrm{b}}$

54.361311

$54.360839^{e}$

$0.09192095^{b}$
54.361465
$54.361003^{f}$

$0.09192064^{\circ}$

54.361386

$54.360924^{f}$

$\begin{array}{lc}0.09180512^{\mathrm{d}} & 0.09180740^{\mathrm{d}} \\ 54.361304 & 54.361887 \\ 54.360827^{\mathrm{e}} & 54.361410^{\mathrm{e}}\end{array}$

$\begin{array}{cc}0.09183948^{\mathrm{d}} & 0.09184211^{\mathrm{d}} \\ 54.361290 & 54.361963\end{array}$

$54.360818^{\mathrm{e}} \quad 54.361491^{\mathrm{e}}$

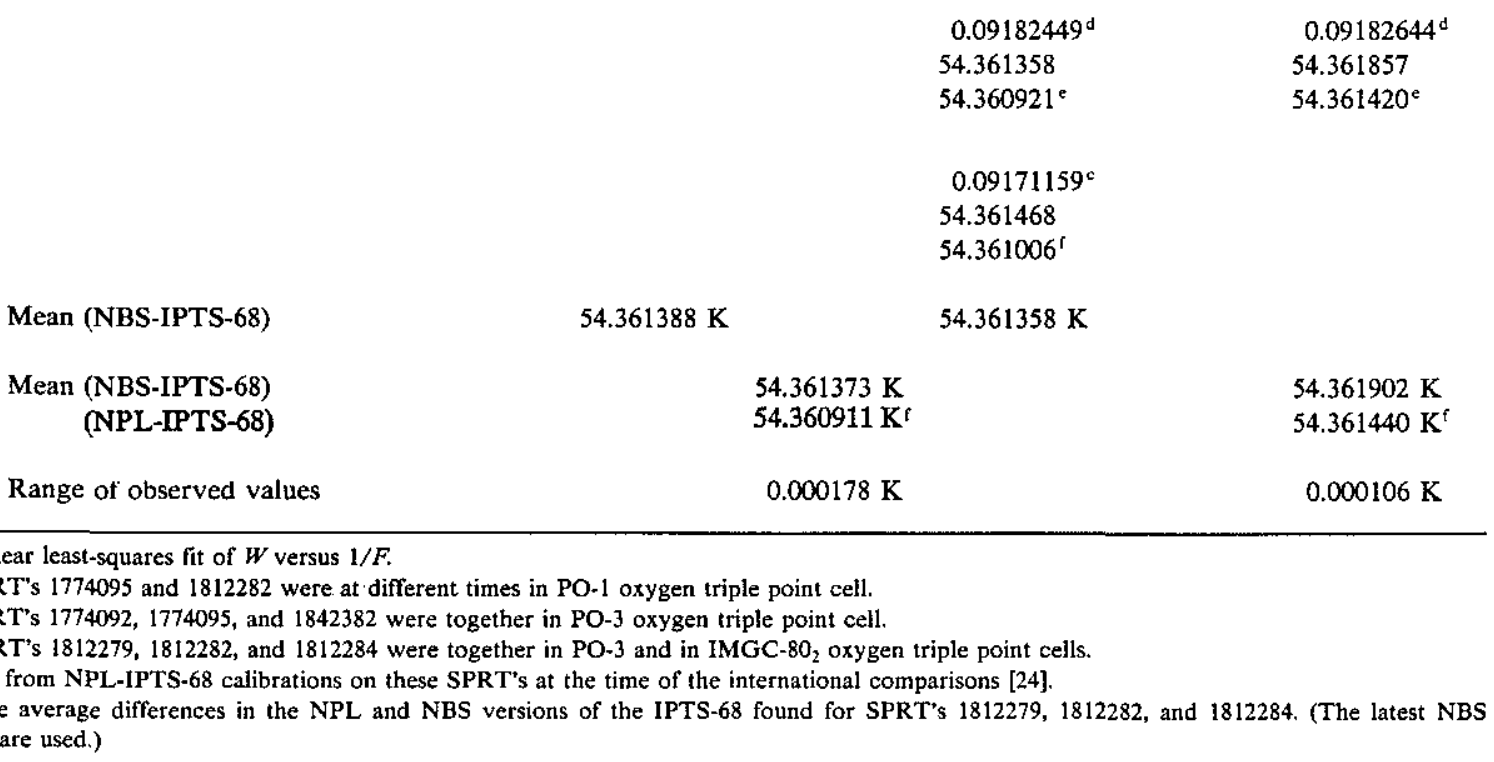

$0.09173132^{\mathrm{c}}$

54.361342

$54.360880^{f}$

a From linear least-squares fit of $W$ versus $1 / F$

b 'The SPRT's 1774095 and 1812282 were at different times in PO-1

c The SPRT's 1774092, 1774095, and 1842382 were together in PO-

d The SPRT's 1812279, 1812282, and 1812284 were together in PO-3

calibrations are used.) 


\section{Journal of Research of the National Bureau of Standards}

1842382 are based on the average difference $(0.462$ $\mathrm{mK}$ ) between the latest calibration of the three international SPRT's on the NBS-IPTS-68 and on the NPL-IPTS-68 at the triple point of oxygen $(54.361 \mathrm{~K})$. The mean NBS-IPTS-68 temperature value given for the two oxygen cells $\mathrm{PO}-1$ and $\mathrm{PO}-$ 3 using the six SPRT's was also converted to the NPL-IPTS-68 temperature value using the above average difference. The ranges of observed values given for cells PO-1 and PO-3 and for cell IMGC$8 \mathrm{O}_{2}$ are based on the NBS-IPTS- 68 values. [To convert the NPL-IPTS-68 temperature values to those on the NBS-IPTS- 68 calibration at the time of the NPL-IPTS-68 comparison, use $+0.588 \mathrm{mK}$ (see footnote e, table 1).]

The values of the triple point of oxygen obtained with cells PO-1 and PO-3 are essentially the same. Their means using different SPRT's differ by only $0.030 \mathrm{mK}$. This indicates that these two cells were filled consistently at different times (February and July of 1983, respectively) from the storage cylinder of prepared oxygen. The high degree of "flatness" of the equilibrium temperatures over a broad range of liquid to solid ratios (or the low impurity content obtained from the "slope," which was mentioned earlier) indicates that the prepared oxygen is purer (see figures 5 and 6 ) than the commercial oxygen samples.

The SPRT's 1774092 and 1774095 were calibrated together, as were the three international SPRT's, but the SPRT 1842382 was not calibrated together with any of the other five SPRT's (see table 1). The SPRT's 1774092, 1774095, and 1842382 were measured together in the oxygen triple point cell PO-3; also the three international SPRT's were used together in cell PO-3. The mean triple point value $54.361364 \mathrm{~K}$ (S.D. $=0.031 \mathrm{mK}$ ) for SPRT's 1774092 and 1774095 is only $0.047 \mathrm{mK}$ higher than the mean value $54.361317 \mathrm{~K}$ (S.D. $=0.036 \mathrm{mK}$ ) for the three international SPRT's. On the other hand, the value $54.361468 \mathrm{~K}$ for SPRT 1842382 is $0.151 \mathrm{mK}$ higher than the mean for the international SPRT's. The figure $0.151 \mathrm{mK}$ is probably the combined inconsistency (spread) of the averages of calibrations and oxygen triple point measurements with the six SPRT's. [This figure turns out fortuitously to be the same as the maximum change in the calibration of the international set of SPRT's (see table 1).]

The following discussions, unless stated otherwise, are in terms of the NBS-IPTS-68. The mean of the observations (range: $0.079 \mathrm{mK}$ ) with cells PO-1 and PO-3 using SPRT 1774095 is 54.361426 $\mathrm{K}$. The triple point of cell $\mathrm{CO}-7$ using the same SPRT is $0.940 \mathrm{mK}$ higher than the above mean of cells PO-1 and PO-3. The amount of argon impurity ( $5 \mathrm{ppm}$, quoted by the supplier) is not enough to cause this increase in terms of the increase of about $10 \mu \mathrm{K}$ per ppm of argon found by Ancsin [3] or about $15 \mu \mathrm{K}$ per ppm found by Compton and Ward [4] by introducing known amounts of argon impurity. The nitrogen impurity ( $3 \mathrm{ppm})$ is expected to lower the triple point of oxygen. The mean of the observations (S.D. $=0.055 \mathrm{mK}$ ) with the IMGC $-8 \mathrm{O}_{2}$ cell using the three international SPRT's is $54.361902 \mathrm{~K}$ and the mean of the four observations (S.D. $=0.030 \mathrm{mK}$ ) with PO- 1 and PO3 cells using the same SPRT's is $54.361321 \mathrm{~K}$. These results indicate that the triple point of the IMGC- $-8 \mathrm{O}_{2}$ cell is $0.581 \mathrm{mK}$ higher than the mean triple point of cells PO-1 and PO-3. This difference is in close agreement with the comparisons of other laboratories of this cell with other oxygen cells [5]. Again the argon impurity ( $3 \mathrm{ppm}$ ) known to be present in the commercial oxygen that was used in IMGC- $80_{2}$ cell cannot account for this higher triple point. Further investigation is required to determine the source of this discrepancy.

Ward and Compton [24] reported as part of the international comparison of the temperature scales the values of $W$ at the oxygen triple point for the international SPRT's 1812279, 1812282, and 1812284. These values are compared in table 3 with the values obtained at the NBS with the same SPRT's for cells PO-1, PO-3, and IMGC-80 2 . The average value for SPRT 1812282 obtained with cells PO-1 and PO-3 is given. These observed values of $W$ for the SPRT's suggest that the oxygen triple point realized at NPL by Compton and Ward [4] is on the average $0.142 \mathrm{mK}$ hotter than the NBS cells PO-1 and PO-3.

Unfortunately, there are only a few SPRT's which were used in both the international comparison of temperature scales [24] and the more recent international comparison of sealed fixed-point cells $[5,24]$. The results of the international comparison of the temperature scales reported by Ward and Compton [24] show that the NPL realization of the oxygen triple point as represented by SPRT 1728839 is $0.1 \mathrm{mK}$ hotter than that realized at the National Measurement Laboratoy (NML, Australia) as represented by SPRT's 1705628 and 1731676. The temperature value reported by NPL using SPRT 1728839 is $0.14 \mathrm{mK}$ smaller than the value reported by NML using SPRT 1731676 on the same oxygen cell in the international comparison of sealed fixed-point cells [5]. These observations are entirely consistent with the difference $+0.142 \mathrm{mK}$ for the realization of the oxygen triple point between NPL and NBS given in table 3; i.e., 


\section{Journal of Research of the National Bureau of Standards}

Table 3. Comparison of the values of the resistance ratio $W$ at the triple point of oxygen.

Capsule Platinum Resistance Thermometer

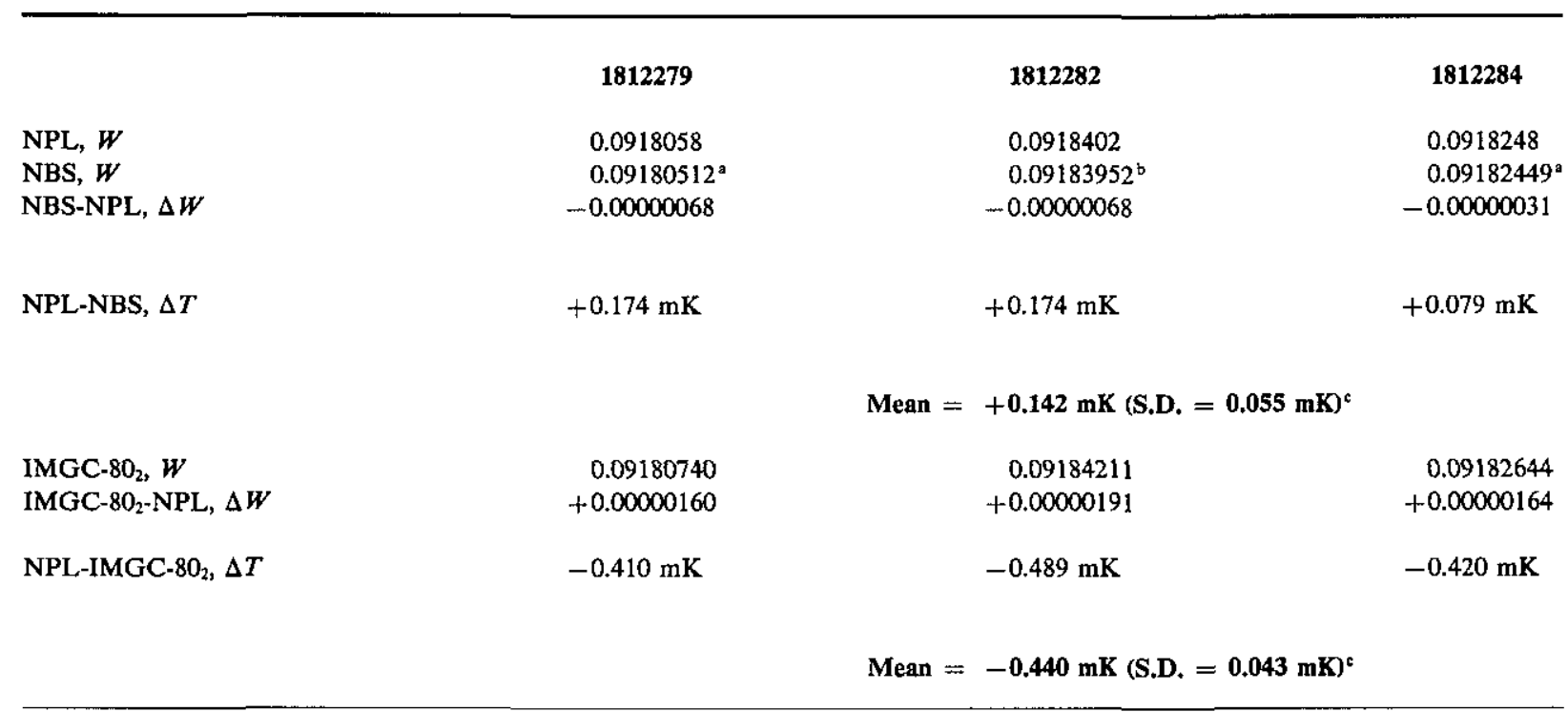

\footnotetext{
"From measurements with NBS oxygen cell PO-3.

"From the average of the measurements with NBS oxygen cells PO-1 and PO-3, taking the two cells to be the "same."

- S.D.=standard deviation of a single observation.
}

the NML realization of the oxygen triple point and the NBS realization of the oxygen triple point with cells PO-9 and PO-3 are very nearly the same, while the NPL realization may be about $0.1 \mathrm{mK}$ hotter.

Ward and Compton [4] used a commercial oxygen containing nitrogen, argon, and krypton impurities. They carefully chemically analyzed their oxygen samples with a sensitivity of $1 \mathrm{ppm}$ for the above impurities [31] and also experimentally determined the effect of these gases on the triple point of oxygen and corrected for their effects [4]. Their corrected oxygen triple point is apparently only $0.142 \mathrm{mK}$ hotter than that of the prepared oxygen of the present investigations. Ancsin [32] reported triple point measurements on "homemade" pure oxygen and commercial oxygen with the supplier analysis in vppm: 15 of argon, 13 of nitrogen, and 10 of krypton. The triple point of the commercial oxygen was shown to be about 0.76 $\mathrm{mK}$ lower than that of the homemade oxygen. Ancsin [32] states that this lowering is much more than could be accounted for by the measured effect of the impurities. Considering the close agreement of the oxygen triple point of cells PO-1 and PO-3 with that of the NPL cell [4] and, in contrast, the deviations found by Ancsin [32] and found in the present work on cells $\mathrm{CO}-7$ and IMGC- $8 \mathrm{O}_{2}$ using commercial oxygen with only supplier analysis, it seems that the analysis of commercial oxygen sam- ples must be improved or there are effects of impurities that have not been accounted.

The results of some of the measurements on the sealed oxygen cells given in the final report on the International Intercomparison of Fixed Points by Means of Sealed Cells [5,30] do not seem to be in complete accord with the above conclusion on the use of commercial oxygen. Table 4 lists, along with the NBS cells, the oxygen triple point cells that were used as part of the above international comparison program. The general statement on the chemical analyses is that they are "nominal" as given by the supplier of the oxygen gas. A few of the analyses may have been obtained by the laboratory that prepared the cell. The report is not explicit on the source of individual analysis. For some of the SPRT's that were used in the measurement, calibrations both of individual laboratories and of the NPL are given (see Appendix II of reference [5]). The calibrations of the NPL had been obtained as part of an earlier investigation on the international comparison of temperature scales represented by SPRT's [24] or were obtained later, either by calibration at the NPL or indirectly by calibration through SPRT's that were so calibrated. In the report the final analysis of the measurements is given in terms of the NPL-IPTS-68. After normalizing to common measurements since there would be variations in the calibrations on the scale, the realized temperatures of the cells of table 


\section{Journal of Research of the National Bureau of Standards}

Table 4. Stated chemical analysis of oxygen samples used in sealed cels for international comparison of fixed points (from Reference [5]).

\begin{tabular}{|c|c|c|c|c|c|c|c|c|c|}
\hline \multirow[t]{2}{*}{ Oxygen Cells ${ }^{\mathrm{a}}$} & \multicolumn{9}{|c|}{ Impurities, Volume Parts per Million (VPPM) } \\
\hline & $\mathbf{H}_{2}$ & $\mathrm{~N}_{2}$ & A & $\mathrm{Kr}$ & & $\mathrm{Xe}$ & $\mathrm{N}_{2} \mathrm{O}$ & $\mathbf{H}-\mathbf{C}^{\mathrm{b}}$ & $\mathrm{CO}_{2}$ \\
\hline IMGC, $1(99.998 \%)=$ & & 8 & $<10$ & $\mathrm{Kr} \div \mathrm{Xe}$ & $=$ & $<1$ & & & \\
\hline IMGC, $8(99.998 \%)^{\circ}$ & & 1.8 & 3 & & & & & 0.7 & \\
\hline INM, $8(99.998 \%)^{c}$ & & 5 & 12 & 3 & & & & & \\
\hline INM, $\mathrm{BCM}^{\circ}$ & $<0.1$ & 5 & 12 & $\mathrm{Kr}+\mathrm{Xe}$ & $=$ & 3 & & $<0.2$ & 0.2 \\
\hline NIM, PP07 & & 3.1 & 0.15 & & & & & 0.15 & $<0.5$ \\
\hline NIM, PPI $(99.999 \%)^{e}$ & & 4.2 & 0.8 & & & & & 0.83 & 0.5 \\
\hline NRC, $15(99.99 \%)^{d}$ & & 20 & 20 & 15 & & 5 & 5 & 10 & 5 \\
\hline
\end{tabular}

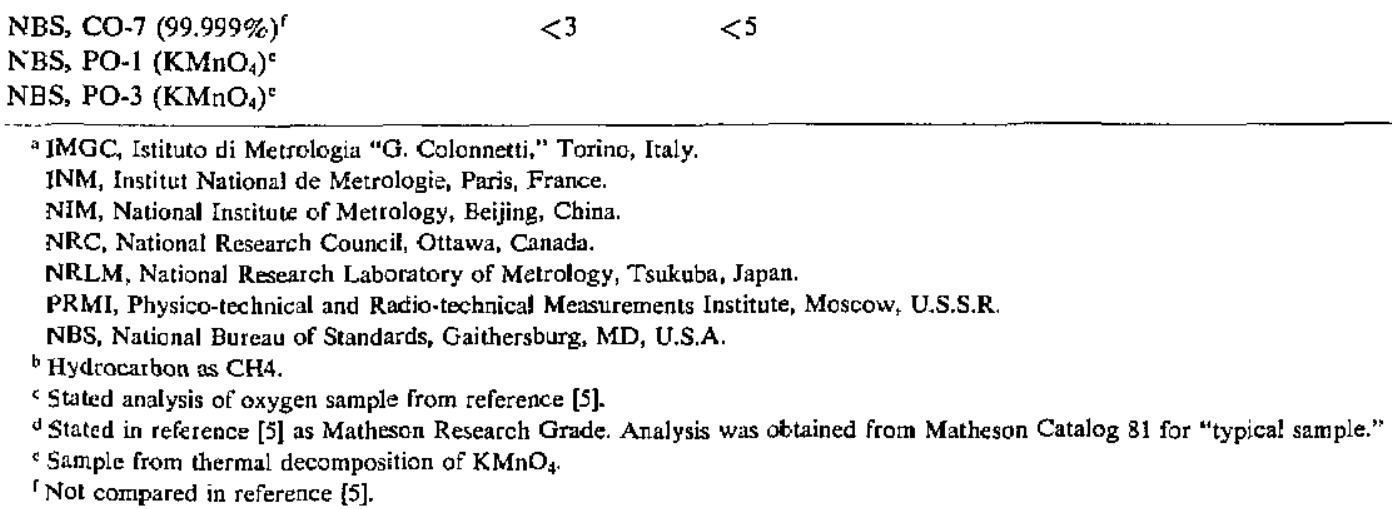

4 (except for cells $1 \mathrm{MGC}-80_{2}$ and $\mathrm{NRLM}$-7801) are found to be within about \pm 0.1 or $\pm 0.2 \mathrm{mK}$ of the IMGC-1 and NRC oxygen cells (see table VI.3b of reference [5]), which are given as $54.36072 \mathrm{~K}$ and $54.36088 \mathrm{~K}$, respectively, on the NPL-IPTS-68. (There are not enough measurements on the PRM1 cell to make any conclusion.) The range of measurements on some of the cells by ASMW (SPRT 217997 ) is $0.17 \mathrm{mK}$, by INM (SPRT 1812283) is $0.04 \mathrm{mK}$, by NIM (SPRT 7709) is $0.14 \mathrm{mK}$, by NML (SPRT 1731676) is $0.10 \mathrm{mK}$, by NPL (SPRT 1728839 ) is $0.16 \mathrm{mK}$, and by NRC (SPRT 1158062) is $0.11 \mathrm{mK}$. Using the difference $0.142 \mathrm{mK}$ given earlier for the realization of the oxygen triple point between NPL and NBS, the triple point of IMGC1 cell becomes $0.14 \mathrm{mK}$ colder than the mean of NBS cells PO-1 and PO-3; the NRC-15 cell comes within $0.02 \mathrm{mK}$ of the NBS cells. This suggests that in spite of the relatively high impurity content of some of the oxygen samples in the cells of table 4, the realized triple points are fairly close to that of the prepared oxygen. It is to be noted, however, that in all of the cells, excluding those indicated earlier as exceptions, the nitrogen impurity content is relatively high. Ancsin [32,3] found the effect on the oxygen triple point by adding $100 \mathrm{vppm}$ of impurities to be : $\mathrm{N}_{2},-2 \mathrm{mK} ; \mathrm{Ar},+1 \mathrm{mK}, \mathrm{Kr},-0.4$ $\mathrm{mK}$; and $\mathrm{Xe},-0.4 \mathrm{mK}$. The effect of the impurities may have closely balanced each other. In the cases of the oxygen cells IMGC-8, NRLM-7801 (chemical analysis not given), and NBS-CO-7, the results indicate that the effect of argon was greater than those of other impurities.

\section{Conclusions}

The results show that oxygen samples purer than the highest quality commercial grade can be prepared by thermal decomposition of $\mathrm{KMnO}_{4}$ and that oxygen triple points can be obtained reproducibly within $\pm 0.1 \mathrm{mK}$ in sealed miniature pressure cells. When carefully handled, capsule-type platinum resistance thermometers can have stability of $\pm 0.1 \mathrm{mK}$ or better. The NBS calibrations of the six NBS SPRT's and the NPL SPRT 1728839 obtained at different times are consistent within about $\pm 0.1 \mathrm{mK}$. When commercial oxygen is used 
in sealed cells, accurate chemical analysis should be obtained on the sample. The triple points of oxygen samples containing a combination of impurities should be investigated since commercial oxygen is expected to have a variety of air components.

The author is grateful to M. L. Reilly for help in the computer analysis of the data.

Certain commercial equipment, instruments, or materials are identified in this paper in order to adequately specify the experimental procedure. Such identification does not imply recommendation or endorsement by the National Bureau of Standards, nor does it imply that the materials or equipment identified are necessarily the best available for the purpose.

\section{References}

[1] The International Practical Temperature Scale of 1968. Amended Edition of 1975, Metrologia 127 (1976).

[2] Pavese, F., Temperature, Its Measurement and Control in Science and Industry (American Institute of Physics, New York, 1982), Vol. 5, Part 1, p. 209.

[3] Ancsin, J., Metrologia 653 (1970).

[4] Compton, J. P., and S. D. Ward, Metrologia 12101 (1976).

[5] Pavese, F., Final Report of the International Intercomparison of Fixed Points by Means of Sealed Cells: 19781984, Bureau International des Poids et Mesures, Monograph 84/4 (1984).

[6] Furukawa, G. T., Temperature, Its Measurement and Control in Science and Industry (American Institute of Physics, New York, 1982), Vol. 5, Part 1, p. 239.

[7] McCullough, J. P., and G. Waddington, Anal. Chim. Acta 1780 (1957).

[8] Guggenheim, E. A., Thermodynamics, An Advanced Treatment for Chemists and Physicists (Interscience Publishers, Inc., New York, 1949), Chap. V.

[9] Hildebrand, J. H., and Scott, R. L., The Solubility of Nonelectrolytes, Third Edition (Dover Publications, Inc., New York, 1964), Chap. 1.
[10] American Institute of Physics Handbook (McGraw-Hill Book Company, Inc., New York, 1972), p. 4-238.

[11] Ruhemann, M., and B. Ruhemann, Low Temperature Physics (Cambridge University Press, London, 1937), Chap. VI.

[12] Veith, H., and E. Schroder, Zeit. phys. Chem. A179 126 (1937).

[13] Din, F.; K. Goldman, and A. G. Monroe, Proceedings Commission I, Ninth International Congress of Refrigeration, Paris, 1955 , p. 1.003.

[14] Rhines, F. N., Phase Diagrams in Metallurgy, Their Development and Application (McGraw-Hill Book Company, Inc., New York, 1956), Chap. 3.

[15] Connolly, J. J., and J. V. McAllan, Acta Met. 231209 (1975).

[16] Yen, W. M., and R. E. Norberg, Phys. Rev. 131269 (1963).

[17] Hood, G. M., and J. N. Sherwood, Mol. Cryst. 197 (1966).

[18] Furukawa, G. T., and M. L. Reilly, J. Res. Nat. Bur. Stand. (U.S.) 74A 617 (1970).

[19] Furukawa, G. T.; M. L. Reilly and W. G. Saba, Rev. Sci. Instr. 35113 (1964).

[20] Westrum, E. F; G. T. Furukawa and J. P. McCullough, in Experimental Thermodynamics, Vol. I, Calorimetry of Non-Reacting Systems, Ed. McCullough, J. P., and D. W. Scott, (Plenum Press, New York, 1968), Chap. 5.

[21] Hoge, H. J., J. Res. Natl. Bur. Stand. (U.S.) 44321 (1950).

[22] Sidgwick, N. V., The Chemical Elements and Their Compounds (Oxford University Press, London, 1950), Vol. II, Chap. VI.

[23] Furukawa, G. T.; J. L. Riddle and W. R. Bigge, J. Res. Natl. Bur. Stand. (U.S.) 77A 309 (1973).

[24] Ward, S. D., and J. P. Compton, Metrologia 1531 (1979).

[25] Bedford, R. E.; M. Durieux, R. Muijlwijk, and C. R. Barber, Metrologia 5, 47 (1969).

[26] Riddle, J. L.; G. T. Furukawa and H. H. Plumb, Platinum Resistance Thermometry, Nat1. Bur. Stand. (U.S.), Monograph No. 126, 1973, 129 pages.

[27] Furukawa, G. T.; J. L. Riddle and W. R. Bigge, J. Res. Natl. Bur. Stand. (U.S.) 80A 477 (1976).

[28] Kusters, N. L.; M. P. MacMartin and R. J. Berry, Temperature, Its Measurement and Control in Science and Industry (Instrument Society of America, Pittsburgh, PA, 1972), Vol. 4, Part 2, p. 1477.

[29] Rosa, E. B., Bull. Bur. Stds. (U.S.) 5413 (1908-1909).

[30] Pavese, F; J. Ancsin, D. N. Astrov, J. Bonhoure, G. Bonnier, G. T. Furukawa, R. C. Kemp, H. Maas, R. L. Rusby, H. Sakurai, and Ling Shan-Kang, Metrologia 20 127-144 (1984).

[31] Compton, J. P., and S. D. Ward, Analyst 99214 (1974).

[32] Ancsin, J., Metrologia 926 (1973). 